\title{
PERUVIAN ECONOMIC ASSOCIATION
}

\section{Financially-Constrained Lawyers}

\author{
Claudia M. Landeo \\ Maxim Nikitin
}

Working Paper No. 52, October 2015

The views expressed in this working paper are those of the author(s) and not those of the Peruvian Economic Association. The association itself takes no institutional policy positions. 


\title{
FINANCIALLY-CONSTRAINED LAWYERS*
}

\author{
CLAUDIA M. LANDEO ${ }^{\dagger}$ and MAXIM NIKITIN ${ }^{\ddagger}$
}

August 3, 2015

\begin{abstract}
Financial constraints reduce the lawyers' ability to file lawsuits and bring cases to trial. As a result, access to justice for true victims, bargaining impasse, and care-taking incentives for potential injurers might be affected. We present the first cradle-to-grave model of legal disputes involving financially-constrained lawyers, third-party lawyer lending, and asymmetric information. In equilibrium, access to justice is denied to some true victims and bargaining impasse occurs. We demonstrate that policies that relax lawyers' financial constraints might be welfare reducing if the positive impact on access to justice is weak and the potential injurers are overdeterred.
\end{abstract}

KEYWORDS: Access to Justice; Social Welfare; Lawsuits; Litigation; Deterrence; Third-Party Litigation Funding; Third-Party Lawyer Lending Industry; Bargaining; Asymmetric Information

JEL Categories: K41, C70, D82

\footnotetext{
${ }^{*}$ Claudia Landeo acknowledges financial support from NSF Grant SES-1155761. We thank Emiliano Catonini, Alexei Parakhonyak, Anton Suvorov, Bart Taub, and especially Sergei Izmalkov and Kathryn Spier for helpful discussions and comments. We also thank comments from participants at the 2015 Stony Brook Game Theory Festival of the Game Theory Society. The authors declare that they have no relevant or material financial interests that relate to the research described in this paper.

${ }^{\dagger}$ University of Alberta, Department of Economics. Henry Marshall Tory Building 7-25, Edmonton, AB T6G 2H4, Canada. landeo@ualberta.ca; corresponding author.

${ }^{\ddagger}$ International College of Economics and Finance, NRU HSE. Shabolovka 26, Moscow 119049, Russia. mnikitin@hse.ru.
} 


\section{Introduction}

The U.S. tort system provides $\$ 172$ billion in gross compensation to plaintiffs each year. Litigation expenses, which are generally covered by personal injury attorneys on behalf of their clients, ${ }^{1}$ represent $\$ 5.2$ billion of this compensation (Engstrom, 2014). The average cost of taking a medical malpractice claim to trial is $\$ 97,000$ (Shepherd, 2014). Expenses on expert witnesses in the $\$ 50,000-\$ 100,000$ range are not uncommon (Trautner, 2009). As cases become more complex and hence, more expensive, attorneys might experience financial constraints. Financial constraints weaken the attorneys' ability to file lawsuits and bring cases to trial. As a result, access to justice for true victims is compromised. In a recent survey (Shepherd, 2014), seasoned medical malpractice lawyers were asked whether they would accept a medical malpractice case with less than $\$ 50,000$ in certain damages. ${ }^{2}$ Only 1.18 percent of the attorneys responded positively. Moreover, 50 percent of the attorneys stated that they would not accept to represent a victim with damages lower than $\$ 250,000$. Over 75 percent of the attorneys indicated that they rejected more than 90 percent of cases due to insufficient damages and/or high litigation expenses. ${ }^{3}$

By affecting the pool of filed cases, lawyers' financial constraints might influence bargaining impasse and care-taking incentives for potential injurers, in addition to impacting access to justice. Policy debate has been centered on the effects of lawyers' financial constraints on access to justice, however. Previous theoretical work on legal disputes has simply abstracted from lawyers' financial constraints. Our paper aims to fill these gaps. We present the first theoretical study of legal disputes in an environment characterized by financially-constrained lawyers, and provide social welfare analysis of empirically-relevant policies.

Traditionally, financing of litigation has involved attorneys' own funding, fellow attorneys' contributions, and bank loans. In the late 1990s, lawyer lenders such as Counsel Financial, among others, started funding activities (Engstrom, 2014). ${ }^{4}$ These lawyer lending institutions

\footnotetext{
${ }^{1}$ See Section 2 for details.

${ }^{2}$ Specifically, the survey question involves a 95 percent likelihood of succeeding at trial.

${ }^{3}$ See also Bell and O'Connell (1997).

${ }^{4}$ See also Garber (2010).
} 
specialize on providing recourse loans (non-contingent loans) to cover the expenses associated with particular legal cases. In contrast to traditional banks, these lenders do not require lawyers' personal assets as collaterals. Instead, the loans are secured by the law firm's assets, including future fees. ${ }^{5}$ The loans involve significantly larger sums and the interest charged is higher than the traditional bank's interest (around 15-20 percent per year). ${ }^{6}$ Our theoretical framework also captures the role of the lawyer's lender industry on legal disputes.

We model the interaction between a defendant, a plaintiff, and a plaintiff's attorney as a sequential game of incomplete information. Our framework is characterized by financiallyconstrained lawyers, third-party lawyer lending, and asymmetric information. The source of information asymmetry is the damage level of the plaintiff's case, which is unknown by the defendant. Our original framework depicts legal disputes from cradle to grave. In particular, our model allows for endogenous care-taking decisions, filing, and out-of-court settlement decisions. We model lawyers' financial constraints by incorporating real-world characteristics of the third-party lawyer lending industry. We construct an equilibrium that includes empirically-relevant features: Accidents do occur in equilibrium; some cases are filed; some lawsuits are dropped, some are resolved out-of-court, and some go to trial. Access to justice is denied to some true victims in equilibrium.

We then assess the effects of policies aimed at lowering the costs associated with legal disputes, and provide social welfare analysis. The interest charged to lawyers by third party lenders and the costs associated with expert witnesses' fees are examples of such costs. ${ }^{7}$ Our findings suggest that cost-reducing policies relax the lawyers' financial constraints. As a result, more low-damage cases are filed. The uninformed defendant reacts by reducing his out-of-court

\footnotetext{
${ }^{5}$ Loans are secured by the estimated value of a firm's total portfolio of cases. Lenders generally require access to the firm's entire docket of cases and assets (Engstrom, 2014).

${ }^{6}$ More recently, a new type of lawyer lending institutions, specialized on non-recourse loans (i.e., loans with repayment contingent on case success), has emerged. This segment of the lawyer lending industry has not experienced significant growth (Engstrom, 2014).

${ }^{7}$ Policies devoted to strengthening competition in the lawyer lending industry might reduce lawyers' financial costs. Similarly, policies designed to increase efficiency of legal procedures and to reduce unpredictability of the legal system might lower the costs associated with litigation (Landeo et al., 2007a, 2007b).
} 
settlement offer, and the likelihood of trial increases. Higher expected litigation costs for the defendant are observed, which increase his care-taking incentives, and lower the probability of an accident. Our results also indicate that cost-reducing policies do not generally benefit true victims or their lawyers: Only low-damage victims whose cases now can proceed to trial are better off; the effect on the attorneys is unambiguously positive only in low-damage cases. We demonstrate that a relaxation of the lawyers' financial constraints might reduce social welfare if the positive effect on access to justice by true victims is weak and the defendant is overdeterred. ${ }^{8}$ The intuition is as follows. As a result of relaxing the lawyer's financial constraints, only few additional true victims get access to justice. In contrast, too many cases proceed to costly trial, and too many resources are spent on accident prevention to avoid costly litigation.

Finally, we extend our benchmark model to conduct social welfare analysis of cost-shifting policies. Several U.S. states have enacted policies that allow attorneys to calculate their contingency fee from the net client's recovery (i.e., after deducting the litigation costs). ${ }^{9}$ Then, attorneys effectively shift a portion of the litigation costs to their clients. We show that that these policies also relax the lawyers' financial constraints, and hence, exhibit the same potential negative welfare effects observed in cost-reducing policies.

Important policy implications follow from our work. Legal commentators are currently proposing the extension of cost-shifting policies by allowing lawyers to shift the financial costs of loans to their clients, in addition to the litigation costs (Engstrom, 2014). They argue that these policies will be welfare-enhancing. We contribute to this debate by underscoring the importance of assessing cost-shifting policies in terms of their effects on access to justice for true victims and their effects on care-taking incentives for potential injurers. In particular, our analysis, which also applies to this type of cost shifting policies, suggests that these reforms might reduce social welfare.

\footnotetext{
${ }^{8}$ See the discussion presented in Section 5 .

${ }^{9}$ U.S. states generally allow lawyers to deduct their contingency fees from the plaintiffs' gross or net recovery, requiring only that the clients be informed "whether ... expenses are to be deducted before or after the contingent fee is calculated" (Model Rules of Professional Conduct, R. 1.5 (c)). New York, Kansas, and New Jersey explicitly require that litigation costs be deducted before the contingency fee is calculated.
} 
Our work provides significant contributions to the theoretical law and economics literature on litigation. ${ }^{10}$ To the best of our knowledge, Landeo et al. (2007b) and Hylton (2002, 1993) are the only three papers that analyze liability and litigation using asymmetric-information models that allow for endogenous care-taking decisions, filing and bargaining impasse. We extend this literature by providing the first formal analysis of legal disputes in an environment that allows for financially-constrained lawyers and third-party lawyer lending, in addition to asymmetrically-informed litigants; and, by incorporating the assessment of access to justice to the welfare analysis of public policies.

Our paper is also related to the small theoretical literature on third-party financing of litigation (Avraham and Wickelgren, 2014; Daughety and Reinganum, 2014; Deffains and Desrieux, forthcoming; Demougin and Maultzsch, 2014; Hylton, 2012; Spier and Prescott, 2015). These previous studies are focused on the effects of third-party plaintiff lending on bargaining impasse. ${ }^{11}$ Our work enhances the understanding of the third-party litigation funding industry by focusing on third-party lawyer lending. In contrast to the previous literature, our framework allows for the analysis of access to justice for true victims, care-taking incentives for potential injurers, filing incentives for lawyers, and social welfare, in addition to the analysis of bargaining impasse.

The rest of the article is organized as follows. Section Two presents the setup of the benchmark model. Section Three outlines the equilibrium analysis. Section Four discusses the effects of a cost-reducing policy on equilibrium strategies and payoffs. Section Five provides a social welfare analysis of a cost-reducing policy. Section Six extends our benchmark model to study the social welfare effects of a cost-shifting policy. Section Seven presents concluding remarks. Appendices A and B, available online, present the formal analysis of the benchmark model and the cost-shifting model.

\footnotetext{
${ }^{10}$ See Shavell (1982), Bebchuk (1984), Reinganum and Wilde (1986), Png (1987) and Spier (1992) for seminal theoretical work on litigation. See Daughety and Reinganum (2012) and Landeo (2015) for recent surveys of theoretical and experimental work on settlement and litigation.

${ }^{11}$ Daughety and Reinganum (2014) also study care-taking incentives for potential injurers.
} 


\section{Model Setup}

This section describes the game stages, the lawyer's financial constraint component, and the no-access to justice component. It also introduces the notation.

\subsection{Game Stages}

We model the interaction between a potential defendant, ${ }^{12}$ a potential plaintiff, and a potential plaintiffs' attorney as a sequential game of incomplete information. The source of information asymmetry is the damage level of the potential plaintiff's case $A$, which is unknown by the defendant. The stages of the game are as follows.

\subsubsection{Care-Taking Stage}

In the first stage, the potential defendant decides his level of care, which determines the probability of accident $\lambda$. The cost of care is denoted by $K(\lambda)$ with $\lim _{\lambda \rightarrow+0} K(\lambda)=+\infty$ and $K(1)=0$. We assume that all potential defendants have the same cost of care, which is common knowledge. We also assume that $K(\lambda)$ is a continuous and differentiable function defined on the interval $(0,1]$ with $\frac{\partial K(\lambda)}{\partial \lambda}<0, \lim _{\lambda \rightarrow 0} \frac{\partial K(\lambda)}{\partial \lambda}=+\infty$, and $\lim _{\lambda \rightarrow 1} \frac{\partial K(\lambda)}{\partial \lambda}=0$, and that $\frac{\partial K(\lambda)}{\partial \lambda}$ is a continuous and differentiable function with $\frac{\partial K^{2}(\lambda)}{\partial \lambda^{2}}>0$. The potential injurer's optimal level of care, i.e., the optimal $\lambda_{D}$, is the one that minimizes the defendant's total expected loss $L_{D}(\lambda)=K(\lambda)+\lambda l_{D}$, where $l_{D}$ is the expected litigation loss. We take the expected litigation loss as parametric in order to describe $L_{D}$, but ultimately $l_{D}$ will be derived as the continuation value of the litigation stage, and hence, it will reflect the outcomes at the litigation stage. We assume that accident occurrence is common knowledge.

If an accident occurs, Nature first determines the merit of the potential plaintiff's case and informs this to the potential plaintiff only. A sufficiently large mass $\mu$ of potential plaintiffs learn that their cases are non-meritorious (damage $A=0$ ), and a mass 1 of potential plaintiffs learn that they have meritorious cases (damage $A>0$ ). Then, the mass of potential plaintiffs is equal to $1+\mu$. The information about the mass of non-meritorious and meritorious cases is

\footnotetext{
${ }^{12}$ We use the terms "potential defendant," "potential injurer," and "defendant" interchangeably.
} 
common knowledge. Second, if the potential plaintiff has a meritorious case $(A>0)$, Nature determines the damage level and informs this to the potential plaintiff only. We assume that the damage levels, conditional on $A>0$, are distributed according to the probability density function $g(A)$ and the cumulative distribution function $G(A)$, with support $(0, \bar{A}]$. We also assume that $g(A)$ is a continuous and differentiable function, and $\bar{A}$ is sufficiently large. The distributions and $\bar{A}$ are common knowledge.

\subsubsection{Filing Stage}

If an accident occurs, the second stage starts. We assume that the mass of potential attorneys is greater than or equal to $1+\mu$, i.e., it is sufficiently high to serve all potential plaintiffs with meritorious and non-meritorious cases. The potential plaintiff and his potential attorney meet. ${ }^{13}$ The attorney, who perfectly observes the potential plaintiff's type (damage level), decides whether to take the case and file a lawsuit. We denote the mass of filed cases as $\zeta$. The attorney is hired under a contingency-fee compensation. Under this scheme, the attorney receives gross payment equal to a share $\gamma$ of the plaintiff's gross recovery (award at trial or out-of-court settlement amount). The attorney's share $\gamma$ is an exogenous constant, known by all parties. The filing costs for meritorious and non-meritorious cases (frivolous cases) are $f_{M}$ and $f_{F}$, respectively, where $f_{F}>f_{M} \cdot{ }^{14}$ These costs are observed only by the plaintiffs and their attorneys but the magnitudes are common knowledge. The plaintiff's attorney pays the filing cost. ${ }^{15}$

\subsubsection{Litigation Stage}

If a lawsuit is filed, the third stage starts. The uninformed defendant makes a take-it-orleave-it out-of-court settlement offer to the plaintiff. The plaintiff then decides whether to accept or reject the defendant's offer. If an offer $S>0$ is accepted by the plaintiff, then the

\footnotetext{
${ }^{13}$ For simplicity, our framework abstracts from searching costs.

${ }^{14}$ For simplicity, our framework truncates the lawyer's decision to accept a client and his decision to file a lawsuit. The "filing cost" encompasses both costs. We assume that the initial evaluation associated with the acceptance of a client is more difficult when the case is non-meritorious. Then, $f_{F}>f_{M}$.

${ }^{15}$ Following empirical regularities, we assume that the plaintiff is financially constrained.
} 
defendant transfers the settlement amount to the plaintiff, and the game ends. Acceptance of a zero offer implies that the plaintiff drops the case. If an out-of-court settlement offer is rejected, the case proceeds to costly trial. We denote the probability of trial as $\rho$. Both litigants incur litigation costs: $C_{P}$ denotes the plaintiff's litigation cost, which is paid by his attorney; and, $C_{D}$ denotes the defendant's litigation cost. We assume that the court perfectly observes the plaintiff's type. Then, non-meritorious cases never succeed at trial (they get a zero recovery). When a meritorious case goes to trial, the court orders the defendant to pay $A>0$ to the plaintiff. ${ }^{16}$ The plaintiff gets $(1-\gamma) A$ at trial and his attorney gets a net payoff of $\gamma A-C_{P}-f_{M}>0$.

\subsection{Lawyer's Financial Constraint Component}

This section describes the lawyer's financial constraint component of our model. We denote the amount of the lawyer's own funds as $x>f_{i}, i=F, M$. We assume that the lawyer is financially constrained. His own funds $x$ are insufficient to bring a case to trial, i.e., $x<f_{i}+C_{P}$, $i=F, M$. We also assume that there are available third-party lawyer lenders that can lend money to the lawyer to allow him to bring a case to trial, and that the third-party lawyer lending industry is not perfectly competitive. ${ }^{17}$ Lawyers with non-meritorious cases know that their cases will never succeed at trial, and hence, do not request loans. In order to be able to bring a meritorious case to trial, the financially-constrained attorney needs to borrow $C_{P}+f_{M}-x$ at a net interest rate $r$. We denote $\tilde{A}$ as the damage threshold at which proceeding and not proceeding to trial provide the same expected payoff for the lawyer, $\gamma \tilde{A}-C_{P}-f_{M}-\left(C_{P}+f_{M}-x\right) r=-f_{M}$. In other words, lawyers with cases $A<\tilde{A}$ will not proceed to trial. Hence, $\tilde{A}$ represents the lawyer's financial constraint.

\footnotetext{
${ }^{16}$ We assume that the court applies a strict liability rule. Under this rule, the injurer has to bear the costs of the accident regardless of the extent of his precaution.

${ }^{17}$ This assumption is empirically relevant. The specialized nature of the service provided by these lenders might act as a barrier to entry. As a result, lenders might have market power.
} 
DEFINITION 1. The lawyer's financial constraint $\tilde{A}$ is defined as follows.

$$
\tilde{A}=\frac{C_{P}+\left(C_{P}+f_{M}-x\right) r}{\gamma} .
$$

Potential plaintiffs with $A \geq \tilde{A}$ are called "high-damage cases," and potential plaintiffs with $0<A<\tilde{A}$ are called "low-damage cases." Remember that a measure 1 represents the meritorious potential plaintiffs. It encompasses high- and low-damage potential plaintiffs. Then, $G(\tilde{A})$ represents the mass of low-damage potential plaintiffs, and $1-G(\tilde{A})$ represents the mass of high-damage potential plaintiffs. Remember also that $\mu$ denotes the mass of no-merit potential plaintiffs $(A=0)$. Then, $1+\mu$ represents the mass of high-, low-, and no-damage potential plaintiffs. We denote the mass of low-damage and no-damage cases that are filed as $\nu$. We assume that the lawyer's financial constraint $\tilde{A}$ is common knowledge. In particular, the plaintiff knows that the lawyer's financial constraint allows only high-damage cases $(A \geq \tilde{A})$ to proceed to trial.

\subsection{No-Access to Justice Component}

This section describes the "No-Access to Justice" component of our model. The "No-Access to Justice" component $\eta$ represents the inability of meritorious (potential) plaintiffs to get access to justice.

DEFINITION 2. No-Access to Justice $\eta$ is defined as the sum of two terms.

(1) The mass of meritorious cases that are not filed.

(2) The mass of meritorious cases that receive a zero offer and cannot proceed to trial.

Intuitively, the first term represents the inability of lawyers with meritorious cases to file a lawsuit. The second term represents the inability of meritorious plaintiffs to get compensation for the inflicted injury through a strictly positive out-of-court settlement transfer or an award at trial. ${ }^{18}$

\footnotetext{
${ }^{18}$ The specific elements included in $\eta$ depend on the equilibrium outcomes. See the analysis of Case 1 in Section 5.1, and the analysis of Cases 2 and 3 in Section 2.2.4 in Appendix A.
} 


\section{Equilibrium Analysis}

In equilibrium, the lawyers' financial constraints permeate the decisions of all the parties involved in a legal dispute. We demonstrate that the magnitude of the prevalent lawyers' financial constraints (the state of the world) determines the damage composition of the equilibrium mass of filed cases. One of three mutually-exclusive scenarios arise in equilibrium: Case 1, under "Strong Financial Constraints;" Case 2, under "Medium Financial Constraints;" and, Case 3, under "Mild Financial Constraints." The composition of the equilibrium mass of filed cases is as follows: All high-damage and some low-damage cases are filed in Case 1; all highand low-damage cases are filed in Case 2; in addition to all high- and low-damage cases, some no-damage cases are filed in Case 3. Across cases, bargaining impasse occurs in equilibrium. Specifically, the uninformed defendants randomize between making a zero offer and a strictly positive offer. Due to asymmetric information, some high-damage plaintiffs receive an insufficiently high offer and proceed to costly trial, some low- and no-damage plaintiffs receive a generous offer and settle out-of-court, and some no-damage and low-damage plaintiffs receive a zero offer and need to drop their cases.

We show that access to justice for true victims is compromised. In Case 1, access to justice is affected by two sources. First, some low-damage cases are not filed. Second, among the low-damage cases filed, some plaintiffs receive a zero offer and are forced to drop their cases. Then, some low-damage plaintiffs do not get access to justice. In Cases 2 and 3, access to justice is compromised by only one source. Although all low-damage cases are filed, some low-damage plaintiffs receive a zero offer and are forced to drop their cases. ${ }^{19}$ Hence, access to justice is still denied to some true victims.

The equilibrium constitutes a perfect Bayesian equilibrium of the game under the following

\footnotetext{
${ }^{19}$ In other words, in Cases 2 and 3, the first term stated in Definition 2 is an empty set. See Section 2.2.4 in Appendix A.
} 
conditions. $^{20}$

$$
\begin{gathered}
f_{F}<\gamma \tilde{A} . \\
\mu>\frac{\int_{\tilde{A}}^{\bar{A}}\left(A+C_{D}\right) g(A) d A}{\tilde{A}}-1 .
\end{gathered}
$$

There exists $\kappa>0$ such that for any $A \in(\tilde{A}, \bar{A})$

$$
g(A)-C_{D} \frac{\partial g(A)}{\partial A}>\kappa
$$

Although the model is solved formally in Appendix A, next we outline the main steps of the solution.

\subsection{Potential Composition of the Set of Equilibrium Offers}

First, we demonstrate that offers lower than zero and greater than $\bar{A}$ are not in the set of equilibrium offers. Similarly, offers greater than zero and lower than $\tilde{A}$ are not in the set of equilibrium offers. It is simple to show that these offers are strictly dominated by a zero offer.

Second, we show that a zero offer must be in the set of equilibrium offers. If a zero offer is not an equilibrium offer, then the defendant will always offer at least $\tilde{A}$. Assuming that $f_{F}$ is low enough (ensured by condition (2)), all non-meritorious cases will be filed. The defendant will lose no less than $(1+\mu) \tilde{A}$, where $\mu$ is the measure of non-meritorious potential plaintiffs. Assuming $\mu$ is large enough (ensured by condition (3)), this loss will be greater than the

loss from making the zero offer, $\int_{\tilde{A}}^{\bar{A}}\left(A+C_{D}\right) g(A) d A$. Hence, a zero offer must be made in equilibrium.

Third, we show that a zero offer cannot be the only offer. If the defendant always makes a zero offer, then, only cases with types $A \geq \hat{A} \equiv \frac{C_{P}+f_{M}+\left(C_{P}+f_{M}-x\right) r}{\gamma}$ will be filed. Attorneys with non-meritorious plaintiffs $(A=0)$ and attorneys with plaintiffs of type $A \in(0, \hat{A})$ will not be willing to file lawsuits, as they expect negative expected payoffs. But then a zero offer will not be an equilibrium offer. The defendant can offer $\hat{A}+\epsilon$ and save litigation costs $C_{D}$

\footnotetext{
${ }^{20}$ Conditions (2) and (3) ensure that a zero offer is made in equilibrium. Condition (4) ensures the existence and uniqueness of the equilibrium positive settlement offer $S$ and the equilibrium mass of low-damage and no-damage cases that are filed $\nu$.
} 
when facing a plaintiff of a type $\hat{A} \leq A \leq \hat{A}+\epsilon$. If $\epsilon<C_{D}$, the defendant's expected litigation

loss will be $\int_{\hat{A}}^{\hat{A}+\epsilon}(\hat{A}+\epsilon) g(A) d A<\int_{\hat{A}}^{\hat{A}+\epsilon}\left(A+C_{D}\right) g(A) d A$. Hence, there must be at least one positive offer $S$ in the set of equilibrium offers.

\subsection{Potential Composition of the Equilibrium Mass of Filed Cases}

First, we demonstrate that there must be no-damage cases $(A=0)$ or low-damage cases $(0<A<\tilde{A})$ that are filed. Otherwise, a zero offer will not be an equilibrium offer. ${ }^{21}$

Second, we show that an attorney with a low-damage or no-damage client is willing to file a lawsuit. Low-damage and no-damage plaintiffs always accept an out-of-court settlement offer because their cases cannot proceed to trial. A positive probability of getting a positive expected offer $E(S)$ ensures a non-negative net payoff for the attorney with a low-damage or no-damage client: $\gamma[b \bullet 0+(1-b) E(S)]-f_{M} \geq 0$, where $(1-b)$ is the probability of getting a positive expected offer.

Third, we demonstrate that high-damage cases $(A \geq \tilde{A})$ are always filed. For a highdamage case, the attorney's expected payoff at the filing stage is $(1-b) \gamma E(S)+b\left[\gamma A-C_{P}-\right.$ $\left.\left(C_{P}+f_{M}-x\right) r\right]-f_{M}$. The last expression is non-negative for $A=\tilde{A}$ and strictly positive for $A>\tilde{A}$.

\subsection{Equilibrium $S$ and $\nu$}

Next, we show that the equilibrium positive settlement offer $S$ and the equilibrium mass of no-damage and low-damage cases that are filed $\nu$ exist and are unique.

We have demonstrated that attorneys with high-damage cases will always file lawsuits, and some attorneys with low-damage or no-damage cases will also file lawsuits. We have also established that there are at least two offers, a zero offer and some $S \geq \tilde{A}$. This implies that the positive offer $S$ must minimize the expected loss of the defendant, and the defendant must

\footnotetext{
${ }^{21}$ See the proof of Proposition 1 in Appendix A for details.
} 
be indifferent between offering zero and $S$. The indifference condition is given by

$$
\nu S+\int_{\tilde{A}}^{S} S g(A) d A+\int_{S}^{\bar{A}}\left(A+C_{D}\right) g(A) d A=\int_{\tilde{A}}^{\bar{A}}\left(A+C_{D}\right) g(A) d A .
$$

The left-hand and right-hand sides of equation (5) represent the defendant's expected losses from making an offer $S>0$ and a zero offer, respectively. Then, the necessary condition for local optimality of $S$ is

$$
\frac{\partial}{\partial S}\left[\nu S+\int_{0}^{S} S g(A) d A+\int_{S}^{\bar{A}}\left(A+C_{D}\right) g(A) d A\right]=0 .
$$

This last equation simplifies to

$$
\nu+G(S)-G(\tilde{A})=C_{D} g(S)
$$

Equation (6) indicates the marginal cost of raising $S$ (represented by the mass of plaintiffs who accept $S$; left-hand side of the equation) equals the marginal benefit of raising $S$ (represented by the savings in litigation cost $C_{D}$ as fewer cases go to trial; right-hand side of the equation).

Assume that $\bar{A}$ is large enough (so that $\bar{A}>S$ ) and that the second-order optimality condition $g(A)>C_{D} \frac{\partial g(A)}{\partial A}$ is satisfied for all $A \in[\tilde{A}, \bar{A}]$ (which is ensured by condition (4)). Lemma 1 in Appendix A demonstrates that the system of equations (5)-(6) has a unique solution, $S$ and $\nu$.

\subsection{Composition of Equilibrium $\nu$}

The prevalent magnitude of the lawyers' financial constraints $\tilde{A}$ (the state of the world) determines one of three mutually-exclusive scenarios: $G(\tilde{A})-\nu>0, G(\tilde{A})-\nu=0$, and $G(\tilde{A})-\nu<0$. We call these three scenarios, Case 1, Case 2, and Case 3, respectively. Lemma 2 in Appendix A shows that a relaxation of the lawyers' financial constraints (i.e., a reduction in $\tilde{A}$ ) lowers $G(\tilde{A})-\nu$. Then, Cases 1, 2, and 3 occur under "Strong," "Medium" and "Mild" lawyers' financial constraints, respectively.

Cases 1, 2, and 3 involve different compositions of equilibrium $\nu$, and hence, different compositions of the equilibrium mass of filed cases $\zeta$. Next, we show how the composition of $\nu$ determines the equilibrium probability that the defendant makes a zero offer $\beta$. 
In Case 1 , the total mass of low-damage cases $G(\tilde{A})$ is greater than the equilibrium mass of low-damage and no-damage cases that are filed $\nu$. Given that $f_{F}>f_{M}$, the equilibrium $\nu$ must be composed of some low-damage cases only. Hence, the equilibrium mass of filed cases $\zeta$ includes some low-damage cases, in addition to all high-damage cases. In this environment, an attorney with an average low-damage client mixes between filing and not filing. ${ }^{22}$ Then, he must be indifferent between these two strategies.

$$
f_{M}=\gamma[\beta \bullet 0+(1-\beta) S]
$$

Intuitively, although low-damage cases cannot proceed to trial, they might still receive a positive out-of-court settlement offer due to asymmetric information. The indifference condition allows us to compute $\beta$, the probability that a defendant makes a zero offer.

$$
\beta=1-\frac{f_{M}}{\gamma S}
$$

An attorney with a no-damage client never files a lawsuit because his expected payoff is negative.

$$
\gamma[\beta \bullet 0+(1-\beta) S]-f_{F}=\gamma\left[\left(1-\frac{f_{M}}{\gamma S}\right) 0+\frac{f_{M}}{\gamma S} S\right]-f_{F}=f_{M}-f_{F}<0
$$

Intuitively, although asymmetry of information might allow the no-damage plaintiff to receive a positive settlement offer, the probability of getting this offer $(1-\beta)$ is too low to cover the lawyer's costs of filing a non-meritorious case $f_{F}>f_{M}$.

In Case 2, the total mass of low-damage cases $G(\tilde{A})$ is equal to the equilibrium mass of lowand no-damage cases that are filed $\nu$. Then equilibrium $\nu$ must be composed by all low-merit cases. Hence, the equilibrium mass of filed cases $\zeta$ includes all low-damage cases, in addition to all high-damage cases. In this environment, an attorney with a low-damage plaintiff must receive a strictly positive expected payoff but an attorney with a no-damage offer must receive a negative expected payoff. Hence, the following condition must hold

$$
f_{F}>\gamma[\beta \bullet 0+(1-\beta) S]>f_{M}
$$

\footnotetext{
${ }^{22}$ In principle, the probability of filing for a low-damage plaintiff may depend on the specific $A$. Then, the expression "average "low-damage client" is used here.
} 
This condition yields a range of values $\beta \in\left(1-\frac{f_{M}}{\gamma S}, 1-\frac{f_{F}}{\gamma S}\right)$.

In Case 3, the total mass of low-damage cases $G(\tilde{A})$ is lower than the equilibrium mass of low- and no-damage cases that are filed $\nu$. Then equilibrium $\nu$ must be composed by all low-damage cases and some no-damage case. Hence, the equilibrium mass of filed cases $\zeta$ includes all low-damage and some no-damage cases, in addition to all high-damage cases. In this environment, the expected payoff for an attorney with a low-damage client must be strictly positive.

$$
\gamma[\beta \bullet 0+(1-\beta) S]-f_{M}=\gamma\left[\left(1-\frac{f_{F}}{\gamma S}\right) \bullet 0+\frac{f_{F}}{\gamma S} S\right]-f_{M}=f_{F}-f_{M}>0
$$

An attorney with a no-damage case will mix between filing and not filing. Hence, he must be indifferent between these two strategies. The indifference condition

$$
\gamma[\beta \bullet 0+(1-\beta) S]-f_{F}=0
$$

allows us to compute $\beta$.

$$
\beta=1-\frac{f_{F}}{\gamma S}
$$

\subsection{Equilibrium $\lambda$}

The equilibrium strategies of the average plaintiff and his attorney and the equilibrium mass of filed cases determine the beliefs of the defendant. ${ }^{23}$

The defendant's optimal probability of an accident is

$$
\lambda_{D}=\arg \min \left\{K(\lambda)+\lambda l_{D}\right\}
$$

where

$$
l_{D}=\int_{\tilde{A}}^{\bar{A}}\left(A+C_{D}\right) g(A) d A
$$

represents the defendant's litigation loss. By Lemma 3 in Appendix A, for any positive value of $l_{D}$, the function $K(\lambda)+\lambda l_{D}$ has a unique interior minimum $\lambda_{D} \in(0,1)$.

Proposition 1 characterizes the equilibrium of the game.

\footnotetext{
${ }^{23}$ Appendix A presents detailed analysis of the construction of the defendant's beliefs.
} 
PROPOSITION 1. Assume that conditions (2)-(4) hold. The following strategy profile, together with the defendant's beliefs, characterize the perfect Bayesian equilibrium of the game.

Case 1: $G(\tilde{A})-\nu>0$

(1) The defendant chooses a probability of accident $\lambda_{D}=\arg \min \left\{K(\lambda)+\lambda \int_{\tilde{A}}^{\bar{A}}\left(A+C_{D}\right) g(A) d A\right\}$. If a lawsuit is filed, the defendant mixes between proposing a zero offer with probability $\beta=$ $1-\frac{f_{M}}{\gamma S}$ and proposing an offer $S>0$ with the complementary probability.

(2) A high-damage case is always filed by the plaintiff's attorney; an average low-damage case is filed with probability $\frac{\nu}{G(\tilde{A})}$; a no-damage case is never filed.

(3) A high-damage plaintiff always rejects a zero offer and accepts an offer $S>0$ only if $A \leq S ;$ a low-damage plaintiff always accepts a non-negative offer; a no-damage plaintiff always accepts a non-negative offer.

(4) The defendant's equilibrium beliefs are as follows. When the defendant observes a lawsuit, he believes that $P(A=0)=0, P(0<A<\tilde{A})=\frac{\nu}{\nu+1-G(\tilde{A})}, P(\tilde{A} \leq A \leq y)=\frac{G(y)-G(\tilde{A})}{\nu+1-G(\tilde{A})}$ for any $y \in[\tilde{A}, \bar{A}]$.

Case 2: $G(\tilde{A})-\nu=0$

(1) The defendant chooses a probability of accident $\lambda_{D}=\arg \min \left\{K(\lambda)+\lambda \int_{\tilde{A}}^{\bar{A}}\left(A+C_{D}\right) g(A) d A\right\}$. If a lawsuit is filed, the defendant mixes between proposing a zero offer with probability $\beta \in$ $\left(1-\frac{f_{F}}{\gamma S}, 1-\frac{f_{M}}{\gamma S}\right)$ and proposing an offer $S>0$ with the complementary probability.

(2) A high-damage case is always filed by the plaintiff's attorney; a low-damage case is always filed; a no-damage case is never filed.

(3) A high-damage plaintiff always rejects a zero offer and accepts an offer $S>0$ only if $A \leq S ;$ a low-damage plaintiff always accepts a non-negative offer; a no-damage plaintiff always accepts a non-negative offer.

(4) The defendant's equilibrium beliefs are as follows. When the defendant observes a lawsuit, he believes that $P(A=0)=0, P(0<A \leq y)=G(y)$ for any $y \in(0, \bar{A}]$.

Case 3: $G(\tilde{A})-\nu<0$

(1) The defendant chooses a probability of accident $\lambda_{D}=\arg \min \left\{K(\lambda)+\lambda \int_{\tilde{A}}^{\bar{A}}\left(A+C_{D}\right) g(A) d A\right\}$. If the plaintiff files a lawsuit, the defendant mixes between proposing a zero offer with proba- 
bility $\beta=1-\frac{f_{F}}{\gamma S}$ and proposing an offer $S>0$ with the complementary probability.

(2) A high-damage case is always filed by the plaintiff's attorney; a low-damage case is always filed; a no-damage case is filed with probability $\frac{\nu-G(\tilde{A})}{\mu}$.

(3) A high-damage plaintiff always rejects a zero offer and accepts an offer $S>0$ only if $A \leq S$; a low-damage case plaintiff always accepts a non-negative offer; a no-damage plaintiff always accepts a non-negative offer.

(4) The defendant's equilibrium beliefs are as follows. When the defendant observes a lawsuit, he believes that $P(A=0)=\frac{\nu-G(\tilde{A})}{\nu+1-G(\tilde{A})}, P(0<A \leq y)=\frac{G(y)}{\nu+1-G(\tilde{A})}$ for any $y \in(0, \bar{A}]$.

Table 1 summarizes the equilibrium outcomes and payoffs. See Section 2.2 in Appendix A for details. For exposition, the rest of the paper will be focused on Case 1. The formal analysis of Cases 2 and 3 is presented in Appendix A.

\section{Comparative Statics: Cost-Reducing Policy}

This section studies the effects of a cost-reducing policy on the equilibrium outcomes and payoffs. Consider, for instance, a policy aimed at reducing the lawyer's financial cost of loans $r$. It is simple to show that a reduction in $r$ lowers $\tilde{A}=\frac{C_{P}+\left(C_{P}+f_{M}-x\right) r}{\gamma} .{ }^{24}$

\subsection{Effects on the Equilibrium Outcomes}

Proposition 2 summarizes the comparative statics results of a reduction in $\tilde{A}$. Our analysis is focused on Case 1. The formal proofs are presented in Appendix A.

PROPOSITION 2. A reduction in $\tilde{A}$ : (1) increases the expected litigation loss of the defendant $l_{D}$; (2) reduces the probability of an accident $\lambda_{D}$; (3) reduces the (strictly) positive

\footnotetext{
${ }^{24}$ More generally, a decrease in $\tilde{A}$ might be also generated by a reduction in the plaintiff's litigation costs $C_{P}$, a reduction in the filing cost $f_{M}$, an increase in the lawyer's share of the plaintiff's gross recovery $\gamma$, or an increase in the lawyer's own funds $x$.
} 
Table 1: Equilibrium Outcomes and Payoffs

\begin{tabular}{ll}
\hline \hline Probability of Accident & $\lambda_{D}=\arg \min \left\{K(\lambda)+\lambda \int_{\tilde{A}}^{\bar{A}}\left(A+C_{D}\right) g(A) d A\right\}$ \\
Mass of Filed Cases & $\zeta=\int_{\tilde{A}}^{\bar{A}} g(A) d A+\nu$ \\
Probability of a Zero Offer ${ }^{(a)}$ & $\beta=\left(1-\frac{f_{M}}{\gamma S}\right), \beta \in\left(1-\frac{f_{M}}{\gamma S}, 1-\frac{f_{F}}{\gamma S}\right), \beta=\left(1-\frac{f_{F}}{\gamma S}\right)$ \\
Probability of Trial & $\rho=\beta[1-G(\tilde{A})]+(1-\beta)[1-G(S)]$ \\
\hline Defendant's Expected Litigation Loss & $l_{D}=\int_{\tilde{A}}^{\bar{A}}\left(A+C_{D}\right) g(A) d A$ \\
\hline Plaintiff's Expected Payoff & \\
- No-Damage $(A=0)^{(b)}$ & $\Pi_{P}=(1-\gamma)[\beta \bullet 0+(1-\beta) S]$ \\
- Low-Damage $(0<A<\tilde{A})$ & $\Pi_{P}=(1-\gamma)[\beta \bullet 0+(1-\beta) S]$ \\
- High-Damage with $A \in[\tilde{A}, S)$ & $\Pi_{P}=(1-\gamma)[\beta A+(1-\beta) S]$ \\
- High-Damage with $A \in[S, \bar{A}]$ & $\Pi_{P}=(1-\gamma) A$ \\
\hline Attorney's Expected Payoff & \\
- No-Damage $(A=0)^{(b)}$ & $\Pi_{P A}=\gamma[\beta \bullet 0+(1-\beta) S]-f_{F}$ \\
- Low-Damage $(0<A<\tilde{A})$ & $\Pi_{P A}=\gamma[\beta \bullet 0+(1-\beta) S]-f_{M}$ \\
- High-Damage with $A \in[\tilde{A}, S)$ & $\Pi_{P A}=\gamma[\beta A+(1-\beta) S]-\beta\left[C_{P}+\left(C_{P}+f_{M}-x\right) r\right]-f_{M}$ \\
- High-Damage with $A \in[S, \bar{A}]$ & $\Pi_{P A}=\gamma A-\left[C_{P}+\left(C_{P}+f_{M}-x\right) r\right]-f_{M}$ \\
\hline
\end{tabular}

Notes: The mass of filed cases is conditional on accident occurrence, and the other outcomes are conditional on accident occurrence and filing; $\Pi_{A}$ and $\Pi_{P A}$ denote the expected payoff for the plaintiff and his attorney, respectively; ${ }^{(a)}$ probability of a zero offer for Cases 1,2 , and 3 , respectively; ${ }^{(b)}$ applies to Case 3 only. 
out-of-court settlement offer $S$; (4) reduces the probability of a zero offer $\beta$; (5) increases the mass of filed cases $\zeta$; and (6) increases the probability of trial $\rho$ if $C_{D}<\tilde{A} .^{25}$

Intuitively, a relaxation of the lawyer's financial constraint (i.e., a reduction in $\tilde{A}$ ), increases access to justice for true victims by inducing more cases with low $A$ to be filed and less lowdamage cases to be dropped (by reducing the likelihood of a zero offer associated with dropping of low-damage cases). ${ }^{26}$ Given the asymmetry of information between the plaintiff and the defendant, the higher likelihood of confronting plaintiffs with low $A$ induces the defendant to lower the positive settlement offer, and hence, increases the likelihood of trial and the litigation costs. As a consequence of the negative impact of the higher likelihoods of filing and trial (and higher litigation costs), which are not offset by the positive effect of the lower settlement offer, the defendant's expected loss increases and hence, his expenses on care also increase. This latter effect reduces the likelihood of accident occurrence. These results also hold in Case 3 and across cases. ${ }^{27}$

\subsection{Effects on the Plaintiff's and Attorney's Payoffs}

The effects of a cost-reducing policy on the average expected payoffs for the plaintiff and his attorney are generally ambiguous. ${ }^{28}$ They depend on the value of $A$ relative to the old and new thresholds and the old and new equilibrium positive offers.

Let $\tilde{A}^{\prime}<\tilde{A}$ and $S^{\prime}<S$ denote the new threshold and the new equilibrium offer, respectively. Table 2 summarizes the five cases studied. For each case, the first and second column

\footnotetext{
${ }^{25}$ Intuitively, if the defendant's litigation costs are low enough, then a reduction in $\tilde{A}$ increases the probability of trial. This is a sufficient (but not necessary) condition. See the proof in Appendix A for details.

${ }^{26}$ Given that a reduction in $\tilde{A}$ lowers the settlement offer $S>0$, and given the inverse relationship between a settlement offer $S>0$ and the probability of making that offer $(1-\beta)$, the probability of making a zero offer $\beta$ will decrease.

${ }^{27}$ The analysis also applies to Case 3 and across cases because the algebraic expressions for the equilibrium outcomes are similar across cases. Result (6) may be violated if a shift between cases occurs. This violation becomes immaterial when $f_{M}$ is infinitely close to $f_{F}$ because $\beta_{1}$ will converge to $\beta_{3}$. Case 2 is a borderline case. Any change in $\tilde{A}$ will shift the equilibrium from Case 2 to Case 1 or to Case 3.

${ }^{28}$ Average expected payoffs are presented in Section 2.2.1 in Appendix A.
} 
Table 2: Effects of a Cost-Reducing Policy on Plaintiff's and Attorney's Payoffs

\begin{tabular}{llllll}
\hline \hline \multicolumn{2}{c}{ Plaintiff's Type Position } & & \multicolumn{2}{c}{ Payoff Effect } \\
\cline { 1 - 2 } \cline { 5 - 6 } Before Policy & After Policy & & $\Pi_{P}$ & $\Pi_{P A}$ \\
\hline $0<A<\tilde{A}$ & $0<A<\tilde{A}^{\prime}$ & & 0 & 0 \\
$0<A<\tilde{A}$ & $A>\tilde{A}^{\prime}$ & & + & + \\
$\tilde{A}<A<S$ & $\tilde{A}^{\prime}<A<S^{\prime}$ & & - & $+/-/ 0$ \\
$\tilde{A}<A<S$ & $A>S^{\prime}$ & & - & $+/-/ 0$ \\
$A>S$ & $A>S^{\prime}$ & & 0 & + \\
\hline
\end{tabular}

Notes: $\Pi_{A}$ and $\Pi_{P A}$ denote the expected payoff for the plaintiff and his attorney;,,+- , and 0 denote positive change, negative change, and no effect, respectively.

refer to the old and new position of $A$, respectively. Appendix A presents the discussion of all cases.

\subsubsection{Effects on the Plaintiff's Payoff}

Our discussion will be focused on the cases in which the plaintiff's expected payoff is affected by a cost-reducing policy. Some initially low-damage plaintiffs are better off. Specifically, in the second case $\left(0<A<\tilde{A}\right.$ and $\left.A>\tilde{A}^{\prime}\right)$, the plaintiff can now proceed to trial and get a strictly positive payoff. Before the policy, the case was dropped (a zero offer was accepted). However, some high-damage plaintiffs are worse off. In the third case $(\tilde{A}<A<S$ and $\tilde{A}^{\prime}<A<S^{\prime}$ ), the positive effect of an increase in the probability of a strictly positive offer less than offsets the negative effect of a reduction in the strictly positive offer. As a result, the plaintiff's expected payoff is reduced. Similarly, in the fourth case $\left(\tilde{A}<A<S\right.$ and $\left.A>S^{\prime}\right)$, the plaintiff is worse off. He now proceeds to trial with certainty and gets an award equal to $A$. Then, a generous expected payoff (due to a settlement offer greater than $A$ ) is now replaced with a lower payoff. 


\subsubsection{Effects on the Attorney's Payoff}

The attorney's expected payoff depends directly on $C_{P}, f_{M}$, and $r$, which also affect $\tilde{A}$. Then, only an evaluation of the effects of individual factors can be implemented. Consider the effect of a reduction in the lawyer's financial cost $r$. Our discussion will be focused on the cases in which the attorney is unequivocally better off.

Our analysis suggests that only in the second and fifth cases, the attorney is unequivocally better off. Consider the second case $\left(0<A<\tilde{A}\right.$ and $\left.A>\tilde{A}^{\prime}\right)$. The initially low-damage case can now proceed to trial. Then, a zero offer is replaced with a strictly positive offer. This effect is aligned with the effect of a cost-reducing policy on the plaintiff's payoff. Consider now the fifth case $\left(A>S\right.$ and $\left.A>S^{\prime}\right)$. The high-damage case proceeds to trial, before and after the reduction in $r$. Due to the reduction in the financial cost $r$, the attorney's expected payoff increases.

Summing up, only when a cost-reducing policy allows the initially low-damage plaintiffs to proceed to trial (second case), both the plaintiff and his attorney are unequivocally better off. In this case, access to justice for true victims is also enhanced.

\section{Welfare Analysis: Cost-Reducing Policy}

This section presents the welfare analysis of a cost-reducing policy for Case 1. The main qualitative findings also hold for Case 3. This analysis is presented in Appendix A (Section 2.2.4). ${ }^{29}$

\subsection{Definitions}

Formal definitions of the social welfare components follow.

Consider the "No-Access to Justice" component $\eta$ in Case 1. Given Definition 2,

$$
\eta=\left[\int_{0}^{\tilde{A}} g(A) d A-\nu\right]+\nu \beta
$$

\footnotetext{
${ }^{29}$ Case 2 is a borderline case. Any change in $\tilde{A}$ will shift the equilibrium from Case 2 to Case 1 or to Case 3.
} 
Intuitively, $\eta$ represents the inability of true victims to get access to justice. It takes into account (1) the mass of low-damage potential plaintiffs who cannot file a lawsuit, $\int_{0}^{\tilde{A}} g(A) d A-$ $\nu ;^{30}$ and, (2) the mass of low-damage plaintiffs who file a lawsuit but receive a zero offer, and hence, need to drop their cases, $\nu \beta$.

Let $\theta \geq 0$ be the coefficient of conversion of the "No Access to Justice" term $\eta$ into social welfare loss. In Appendix A (Section 2.2.3), we show that when $\theta=0$, the social welfare function encompasses the sum of the net expected payoffs for all players. ${ }^{31}$ When $\theta>0$, the social welfare function also accounts for the social value of preserving the citizens' right of access to justice. ${ }^{32}$ In Appendix A (Section 2.2.3), we also demonstrate that the minimization of the social welfare loss function is equivalent to the maximization of the social welfare function, across $\theta$ values. Our social welfare analysis will be focused on the minimization of the social welfare loss function under $\theta>0$.

DEFINITION 3. The social loss from litigation $l_{W}$ is defined as follows.

$$
\begin{gathered}
l_{W}=\int_{0}^{\bar{A}} A g(A) d A+\zeta \bullet f_{M}+\rho \bullet\left(C_{P}+C_{D}\right)+\theta \eta= \\
=\int_{0}^{\bar{A}} A g(A) d A+\left[\int_{\tilde{A}}^{\bar{A}} g(A) d A+\nu\right] f_{M}+\left[\beta \int_{\tilde{A}}^{\bar{A}} g(A) d A+(1-\beta) \int_{S}^{\bar{A}} g(A) d A\right]\left(C_{P}+C_{D}\right)+ \\
+\theta\left[\int_{0}^{\tilde{A}} g(A) d A-\nu+\nu \beta\right]
\end{gathered}
$$

The social loss from litigation $l_{W}$ encompasses four main components: (1) total harm from an accident; $(2)$ total filing cost $f_{M} ;(3)$ total legal costs incurred in case of trial $\left(C_{P}+C_{D}\right)$;

\footnotetext{
${ }^{30}$ Remember that $\int_{0}^{\tilde{A}} g(A) d A-\nu=1-\zeta=1-\left[\int_{\tilde{A}}^{\bar{A}} g(A) d A+\nu\right]$, where $\zeta$ is the mass of filed cases.

${ }^{31}$ See Kaplow and Shavell $(2002,2001,1999)$ for discussion on social welfare analysis of pubic policies.

${ }^{32}$ Preserving the right of access to justice is an increasing concern for the U.S. and the international community. The U.S. Department of Justice established the Access to Justice Initiative (ATJ) in March 2010. Similarly, the United Nations considered for the first time including Access to Justice as part of its Sustainable Development Goals (Goal 16) in 2015. See Kornhauser (2015, 2003) for discussion on economic analysis of law and welfare analysis of public policies. See also Chang (2000). For more general discussion on welfare economics, see Deb et al. (1997), Gibbard (1974), Hillinger and Lapham (1971), Sen (1971, 1970), and Diamond (1967).
} 
and, (4) social cost associated with the infringement of some citizens' right of access to justice, represented by the "No Access to Justice" term $\eta$.

DEFINITION 4. The social welfare loss function $S W L$, evaluated at $\lambda_{D}$, is defined as follows.

$$
\begin{gathered}
S W L\left(\lambda_{D}\right)=K\left(\lambda_{D}\right)+\lambda_{D} l_{W}= \\
=K\left(\lambda_{D}\right)+\lambda_{D}\left\{H+\left[\int_{\tilde{A}}^{\bar{A}} g(A) d A+\nu\right] f_{M}+\left[\beta \int_{\tilde{A}}^{\bar{A}} g(A) d A+(1-\beta) \int_{S}^{\bar{A}} g(A) d A\right]\left(C_{P}+C_{D}\right)+\right. \\
\left.+\theta\left[\int_{0}^{\tilde{A}} g(A) d A-\nu+\nu \beta\right]\right\}
\end{gathered}
$$

The social welfare loss function, evaluated at the privately-optimal probability of an accident $\lambda_{D}$, encompasses two main components: (1) Resources devoted to accident prevention $K\left(\lambda_{D}\right)$; (2) (unconditional) social loss from litigation $\lambda_{D} l_{w}$.

Let $\lambda_{W}=\arg \min \left\{K(\lambda)+\lambda l_{W}\right\}$ represent the socially-optimal probability of an accident.

DEFINITION 5. The potential injurer's deterrence level is defined as follows.

(1) Under-Deterred Potential Injurer: $\lambda_{D}>\lambda_{W}$.

(2) Over-Deterred Potential Injurer: $\lambda_{D}<\lambda_{W}$.

By Lemma 3 in Appendix A, $l_{D}<l_{W}$ implies under-deterrence, and $l_{D}>l_{W}$ implies overdeterrence.

\subsection{Social Welfare Analysis}

We analyze the social welfare effect of a cost-reducing policy (i.e., the effect of a reduction in $\tilde{A})$. We demonstrate that the overall effect of a cost-reducing policy is generally ambiguous. If the positive effect on access to justice for true victims is weak and the potential injurers are overdeterred, then this policy is welfare reducing. ${ }^{33}$

\footnotetext{
${ }^{33}$ When $\theta=0$, a cost-reducing policy will be welfare reducing if the potential injurer is overdeterred. If the potential injurer is underdeterred and the positive effect on deterrence is strong enough, then this policy will be welfare improving.
} 
We start our analysis by decomposing the overall welfare effect into two components, indirect and direct effects. The indirect and direct effects capture the impact of a costreducing policy on the potential injurer's care-taking incentives, and on the social welfare loss from litigation, respectively. Then, the indirect and direct effects are computed for a given $l_{W}$ and a given $\lambda_{D}$, respectively.

Mathematically, the overall welfare effect of a reduction in $\tilde{A}$ is given by

$$
\frac{d S W L\left(\lambda_{D}\right)}{d \tilde{A}}=\frac{\partial S W L\left(\lambda_{D}\right)}{\partial \lambda_{D}} \frac{\partial \lambda_{D}}{\partial \tilde{A}}+\frac{\partial S W L\left(\lambda_{D}\right)}{\partial \tilde{A}} .
$$

The first term in the right-hand side of the equation represents the indirect effect while the second term represents the direct effect.

The direct effect can be computed by explicit differentiation:

$$
\frac{\partial S W L\left(\lambda_{D}\right)}{\partial \tilde{A}}=-\lambda_{D} \frac{\left(\tilde{A}+C_{D}\right) G(\tilde{A})}{S} f_{M}+\lambda_{D}\left(C_{P}+C_{D}\right) \frac{\partial \rho}{\partial \tilde{A}}+\lambda_{D} \theta\left[\frac{\partial \eta}{\partial \tilde{A}}\right] .
$$

To compute the indirect effect, we take into account that at the point of the defendant's optimum, $\lambda_{D}$, the first-order optimality condition implies:

$$
\frac{\partial K\left(\lambda_{D}\right)}{\partial \lambda_{D}}=-l_{D}
$$

Differentiating the first-order optimality condition with respect to $\tilde{A}$ yields:

$$
\frac{\partial \lambda_{D}}{\partial \tilde{A}}=-\frac{\frac{\partial l_{D}}{\partial \tilde{A}}}{\frac{\partial^{2} K\left(\lambda_{D}\right)}{\partial \lambda_{D}^{2}}}=\frac{\left(\tilde{A}+C_{D}\right) G(\tilde{A})}{\frac{\partial^{2} K\left(\lambda_{D}\right)}{\partial \lambda_{D}^{2}}}
$$

Then, the indirect effect can be written as:

$$
\frac{\partial S W L\left(\lambda_{D}\right)}{\partial \lambda_{D}} \frac{\partial \lambda_{D}}{\partial \tilde{A}}=\left[\frac{\partial K\left(\lambda_{D}\right)}{\partial \lambda_{D}}+l_{W}\right] \frac{\left(\tilde{A}+C_{D}\right) G(\tilde{A})}{\frac{\partial^{2} K\left(\lambda_{D}\right)}{\partial \lambda_{D}^{2}}}=\left(l_{W}-l_{D}\right) \frac{\left(\tilde{A}+C_{D}\right) G(\tilde{A})}{\frac{\partial^{2} K\left(\lambda_{D}\right)}{\partial \lambda_{D}^{2}}} .
$$

Hence, the overall welfare effect of a cost-reducing policy can be expressed as

$$
\begin{gathered}
\frac{d S W L\left(\lambda_{D}\right)}{d \tilde{A}}=\left[\left(l_{w}-l_{D}\right) \frac{\left(\tilde{A}+C_{D}\right) G(\tilde{A})}{\frac{\partial^{2} K\left(\lambda_{D}\right)}{\partial \lambda_{D}^{2}}}\right]+ \\
+\left[-\lambda_{D} \frac{\left(\tilde{A}+C_{D}\right) G(\tilde{A})}{S} f_{M}+\lambda_{D}\left(C_{P}+C_{D}\right) \frac{\partial \rho}{\partial \tilde{A}}+\lambda_{D} \theta\left(\frac{\partial \eta}{\partial \tilde{A}}\right)\right] .
\end{gathered}
$$

The first and second terms in brackets represent the indirect and direct effects of a costreducing policy, respectively. A detailed analysis of these two effects follows. 


\section{Indirect Welfare Effect}

The indirect effect, $\left[\left(l_{W}-l_{D}\right) \frac{\left(\tilde{A}+C_{D}\right) G(\tilde{A})}{\frac{\partial^{2} K\left(\lambda_{D}\right)}{\partial \lambda_{D}^{2}}}\right]$, is generally ambiguous. It depends on the sign of the term $\left(l_{W}-l_{D}\right)$, i.e., on the relationship between the social loss from litigation and the defendant's private litigation loss. Intuitively, the indirect welfare effect depends on the potential injurer's deterrence level. The welfare effect will be positive if the potential injurer is under-deterred $l_{W}>l_{D} ;{ }^{34}$ otherwise, it will be negative.

More specifically, the social loss from litigation $l_{W}$ is given by equation (12), and the defendant's private expected loss from litigation $l_{D}$ is given by equation (10). Then, the term $\left(l_{W}-l_{D}\right)$ can be expressed as follows.

$$
\begin{gathered}
l_{W}-l_{D}=\left[\int_{0}^{\bar{A}} A g(A) d A-\int_{\tilde{A}}^{\bar{A}} A g(A) d A\right]+ \\
\left.+\left\{\left(C_{P}+C_{D}\right)\left[\beta \int_{\tilde{A}}^{\bar{A}} g(A) d A+(1-\beta) \int_{S}^{\bar{A}} g(A) d A\right)\right]-C_{D} \int_{\tilde{A}}^{\bar{A}} g(A) d A\right\}+ \\
+\left\{\left[\int_{\tilde{A}}^{\bar{A}} g(A) d A+\nu\right] f_{M}+\theta\left[\int_{0}^{\tilde{A}} g(A) d A-\nu+\nu \beta\right]\right\} .
\end{gathered}
$$

The first term in brackets is positive. The third term in curly brackets is also positive. ${ }^{35}$ The second term in curly brackets will be positive if $f_{M}$ is sufficiently lower than $\gamma S .{ }^{36}$ In this case, the sign of the term $\left(l_{W}-l_{D}\right)$ will be unambiguously positive, and hence, the indirect effect of a cost-reducing policy will be welfare enhancing. Otherwise, the indirect effect might be welfare reducing. ${ }^{37}$

\section{Direct Welfare Effect}

The direct effect of a cost-reducing policy on social welfare, $\left[-\lambda_{D} \frac{\left(\tilde{A}+C_{D}\right) G(\tilde{A})}{S} f_{M}+\lambda_{D}\left(C_{P}+\right.\right.$ $\left.\left.C_{D}\right) \frac{\partial \rho}{\partial \tilde{A}}+\lambda_{D} \theta\left(\frac{\partial \eta}{\partial \tilde{A}}\right)\right]$, is also ambiguous. It depends on the sign of the expression in brackets.

\footnotetext{
${ }^{34}$ In this case, a reduction in $\tilde{A}$ will reduce the social welfare loss, and hence, will increase social welfare.

${ }^{35}$ Note that $\eta=\int_{0}^{\tilde{A}} g(A) d A-\nu+\nu \beta$, which is positive. The third term is also positive when $\theta=0$.

${ }^{36}$ If $f_{M}<\gamma S$, then $\beta=1-\frac{f_{M}}{\gamma S}$ will be quite close to unity. Then, $\rho=\beta \int_{\tilde{A}}^{\bar{A}} g(A) d A+(1-\beta) \int_{S}^{\bar{A}} g(A) d A$ should be sufficiently close to $\int_{\tilde{A}}^{\bar{A}} g(A) d A$. Hence, adding $C_{P}$ to $C_{D}$ ensures that the second term will be positive.

${ }^{37}$ These results also hold when $\theta=0$.
} 
Specifically, the direct effect includes two negative welfare effects, the effect of larger filing costs (first term in $f_{M}$ ), and the effect of larger litigation costs (second term in $C_{P}+C_{D}$; $\frac{\partial \rho}{\partial \tilde{A}}<0$, by Proposition 2). It also includes a positive welfare effect (third term in $\theta ; \frac{\partial \eta}{\partial \tilde{A}}>0$, by Lemma 4 in Appendix A). This positive effect will offset the negative effects if the value of $\theta$ (the coefficient of conversion of the No-Access to Justice term $\eta$ into social welfare loss) is large enough. In this case, the sign of the expression in brackets will be positive, and hence, the direct effect of a cost-shifting policy will be welfare improving. Otherwise, the indirect effect will be welfare reducing. ${ }^{38}$

\section{Overall Welfare Effect}

Proposition 3 summarizes the main welfare results.

Define $\underline{\theta}$ as

$$
\underline{\theta}=\frac{\lambda_{D} \frac{\left(\tilde{A}+C_{D}\right) G(\tilde{A})}{S} f_{M}-\lambda_{D}\left(C_{P}+C_{D}\right) \frac{\partial \rho}{\partial \tilde{A}}}{\lambda_{D} \frac{\partial \eta}{\partial \tilde{A}}}
$$

PROPOSITION 3. If the defendant is under-deterred $\left(l_{W}>l_{D}\right)$ and $\theta>\underline{\theta}$, then the welfare effect of a cost-shifting policy is positive; if the defendant is over-deterred $\left(l_{W}<l_{D}\right)$ and $\theta<\underline{\theta}$, then the welfare effect of a cost-shifting policy is negative. ${ }^{39}$

Our analysis demonstrates that cost-reducing policies might be welfare reducing, and underscores the importance of the potential injurer's deterrence level and the No-Access to Justice component.

\footnotetext{
${ }^{38}$ When $\theta=0$, the direct effect will be unambiguously welfare reducing. Hence, a cost-reducing policy will be welfare reducing if the potential injurer is overdeterred (i.e., if the indirect effect is also welfare reducing). If the potential injurer is undeterred (i.e., if the indirect effect is welfare improving) and this indirect effect is strong enough, then a cost-reducing policy will be welfare improving.

${ }^{39} \mathrm{~A}$ sufficiently large (small) value of $\theta$ does not necessarily mean that $\theta$ should be large (small) in absolute sense. It can be just relatively large (small) compared to $\left(C_{P}+C_{D}\right)$ and $f_{M}$, and still satisfy the condition stated in Proposition 3. For instance, if $\left(C_{P}+C_{D}\right)$ and $f_{M}$ become small (large) enough, then $\underline{\theta}$ becomes smaller (larger). As a result, the inequalities described in Proposition 3 will be satisfied for lower (higher) values of $\theta$.
} 


\section{Extension: A Cost-Shifting Model}

We extend our benchmark model to study the welfare effects of a policy that allows attorneys to shift part of the litigation and filing costs to their clients.

In the benchmark model, the attorney calculates his fee from the client's gross recovery, and then deducts expenses out of his own share. In the cost-shifting model, the attorney calculates his fee from the client's net recovery. Hence, the attorney effectively shifts a $(1-\gamma)$ portion of the case-related expenses to the plaintiff.

We assume that the plaintiff's litigation costs $C_{P}=C_{P}^{1}+C_{P}^{2}$, where $C_{P}^{1}$ represents caserelated litigation expenses that can be shifted to the client. ${ }^{40}$ We also assume that the filing cost $f_{M}$ can be shifted to the client. We denote $\tilde{A}^{\prime \prime}$ as the damage level at which proceeding and not proceeding to trial provide the same expected payoff for the lawyer, $\gamma\left(\tilde{A}^{\prime \prime}-C_{P}^{1}-\right.$ $\left.f_{M}\right)-C_{P}^{2}-\left(C_{P}+f_{M}-x\right) r=-f_{M}$. Hence, $\tilde{A}^{\prime \prime}$ represents the lawyer's financial constraint.

DEFINITION 6. The lawyer's financial constraint $\tilde{A}^{\prime \prime}$ is defined as follows.

$$
\tilde{A}^{\prime \prime}=C_{P}^{1}+f_{M}+\frac{C_{P}^{2}+\left(C_{P}+f_{M}-x\right) r-f_{M}}{\gamma} .
$$

Finally, we assume that the lawyer's financial constraint is common knowledge. In particular, the plaintiff knows that the attorney's financial constraint allows only high-damage cases $\left(A \geq \tilde{A}^{\prime \prime}\right)$ to proceed to trial.

It is straightforward to verify that $\tilde{A}^{\prime \prime}<\tilde{A}$, where $\tilde{A}$ corresponds to the threshold value of $A$ under the benchmark model. In other words, a cost-shifting policy reduces the threshold $\tilde{A}$, i.e., relaxes the lawyer's financial constraint. The structure of the equilibrium and comparative statics resemble the benchmark model. ${ }^{41}$ The formal analysis is presented in Appendix B (Lemmas 6-7, Propositions 4-5, and proofs).

The rest of the section will be focused on the social welfare analysis for Case 1 . We

\footnotetext{
${ }^{40}$ In the benchmark model, $C_{P}^{1}=0$, and $C_{P}=C_{P}^{2}$.

${ }^{41}$ In particular, a cost-shifting policy increases the probability of trial and the mass of filed cases. In addition, this policy increases the expected loss of the defendant, and hence, reduces the probability of an accident.
} 
assess the effects of a cost-shifting policy on social welfare by comparing the social welfare loss functions associated with the cost-shifting model and the benchmark model.

Let the terms with and without superscript $\left({ }^{\prime \prime}\right)$ correspond to the equilibrium outcomes for the cost-shifting and the benchmark models, respectively. Let $\Delta=\left(S W L^{\prime \prime}-S W L\right)$ represent the total welfare effect of a cost-shifting policy. A positive welfare effect will be indicated by $\Delta<0$. The total welfare effect $\Delta$ can be decomposed into direct and indirect effects.

$$
\begin{gathered}
\Delta=\left\{\left[K\left(\lambda_{D}^{\prime \prime}\right)+\lambda_{D}^{\prime \prime} l_{W}^{\prime \prime}\right]-\left[K\left(\lambda_{D}\right)+\lambda_{D} l_{W}^{\prime \prime}\right]\right\}+\left\{\left[K\left(\lambda_{D}\right)+\lambda_{D} l_{W}^{\prime \prime}\right]-\left[K\left(\lambda_{D}\right)+\lambda_{D} l_{W}\right]\right\}= \\
=\left\{\left[K\left(\lambda_{D}^{\prime \prime}\right)+\lambda_{D}^{\prime \prime} l_{W}^{\prime \prime}\right]-\left[K\left(\lambda_{D}\right)+\lambda_{D} l_{W}^{\prime \prime}\right]\right\}+\left\{\lambda_{D}\left(l_{W}^{\prime \prime}-l_{W}\right)\right\} .
\end{gathered}
$$

The first expression in curly brackets, $\left\{\left[K\left(\lambda_{D}^{\prime \prime}\right)+\lambda_{D}^{\prime \prime} l_{W}^{\prime \prime}\right]-\left[K\left(\lambda_{D}\right)+\lambda_{D} l_{W}^{\prime \prime}\right]\right\}$, represents the indirect effect, which operates through changes in the potential injurer's care-taking incentives. The second expression in curly brackets, $\left\{\lambda_{D}\left(l_{W}^{\prime \prime}-l_{W}\right)\right\}$, represents the direct effect, which operates through changes in the social loss from litigation. A detailed analysis of these two effects follows.

\section{Indirect Welfare Effect}

The indirect effect of a cost-shifting policy on social welfare, $\left\{\left[K\left(\lambda_{D}^{\prime \prime}\right)+\lambda_{D}^{\prime \prime} l_{W}^{\prime \prime}\right]-\left[K\left(\lambda_{D}\right)+\right.\right.$ $\left.\left.\lambda_{D} l_{W}^{\prime \prime}\right]\right\}$, is generally ambiguous. It depends on the sign of the expression in curly brackets. Intuitively, the indirect welfare effect depends on the potential injurer's deterrence level.

By Proposition 5 in Appendix B, $\lambda_{D}^{\prime \prime}<\lambda_{D}$. Given the assumptions about the function $K(\lambda)$, it is straightforward to show that $K(\lambda)+\lambda l_{W}^{\prime \prime}$ is decreasing on the interval $\left(0, \lambda_{W}^{\prime \prime}\right)$ and increasing on the interval $\left(\lambda_{W}^{\prime \prime}, 1\right)$. Then, the sign of the expression in curly brackets will be negative when $\lambda_{D}^{\prime \prime}>\lambda_{W}^{\prime \prime}$, and hence, the indirect effect will be welfare improving. Otherwise, it will be welfare reducing.

The intuition is as follows. Consider first the case where the defendant was initially underdeterred and is still underdeterred under the cost-shifting policy $\left(\lambda_{D}^{\prime \prime}>\lambda_{W}^{\prime \prime}\right)$. The defendant's

expected litigation loss conditional on accident occurrence $l_{D}^{\prime \prime}$ is lower than the socially optimal litigation loss $l_{W}^{\prime \prime}$. Although the higher private expected litigation loss under the cost-shifting policy forces the potential defendant to increase his spending on care, his level of care is not 
above the socially optimal. Hence, the indirect effect is welfare improving. Second, consider the case where the defendant was initially overdeterred. Then, he will be also overdeterred under the cost-shifting policy $\left(\lambda_{D}^{\prime \prime}<\lambda_{W}^{\prime \prime}\right)$. Too many resources were initially spent on care, and the situation is aggravated by the cost-shifting policy. Hence, the indirect effect of a cost-shifting policy is welfare reducing. ${ }^{42}$

\section{Direct Welfare Effect}

The direct effect of the cost-shifting policy on social welfare, $\lambda_{D}\left(l_{W}^{\prime \prime}-l_{W}\right)$, is also ambiguous. It depends on the sign of the term $\left(l_{W}^{\prime \prime}-l_{W}\right)$. This term can be expressed as

$$
\begin{aligned}
l_{W}^{\prime \prime}-l_{W} & =\left[\int_{0}^{\bar{A}} A g(A) d A+\zeta^{\prime \prime} \bullet f_{M}+\rho^{\prime \prime} \bullet\left(C_{P}+C_{D}\right)+\theta \eta^{\prime \prime}\right]- \\
- & {\left[\int_{0}^{\bar{A}} A g(A) d A+\zeta \bullet f_{M}+\rho \bullet\left(C_{P}+C_{D}\right)+\theta \eta\right]=} \\
& =\left(\zeta^{\prime \prime}-\zeta\right) f_{M}+\left(\rho^{\prime \prime}-\rho\right)\left(C_{P}+C_{D}\right)+\theta\left(\eta^{\prime \prime}-\eta\right) .
\end{aligned}
$$

Equation (21) indicates that a cost-shifting policy affects $\left(l_{W}^{\prime \prime}-l_{W}\right)$ in three ways. There are two negative welfare effects that operate through the larger filing cost (due to higher number of true victims filing a lawsuit) and the larger litigation costs (due to the higher conditional probability of trial). A third welfare effect operates through the change in the No-Access to Justice term $\eta$.

The effect of a cost-shifting policy on the No-Access to Justice term $\eta$ is generally ambiguous. On the one hand, $\eta$ will be lower because of the higher filing and the higher share of true victims that can now proceed to trial (higher share of plaintiffs with $A \geq \tilde{A}^{\prime \prime}$ ). On the other hand, $\eta$ might be higher or lower due to the change in the probability of a zero offer $\beta$, which is generally ambiguous (by Proposition 5 in Appendix B). The following sufficient condition ensures that a cost-shifting policy decreases $\beta$, and hence, decreases $\eta$.

$$
-\gamma\left(S^{\prime \prime}-S\right)>(1-\gamma) f_{M}
$$

\footnotetext{
${ }^{42}$ These results also hold when $\theta=0$.
} 
As a result, a cost-shifting policy will unambiguously reduce $\eta$. Hence, access to justice for true victims will be enhanced.

If the effect on the No-Access to Justice term $\eta$ offsets the effects on filing and litigation costs, then the sign of the term $l_{W}^{\prime \prime}-l_{W}$ will be negative, and hence, the direct effect of a cost-shifting policy will be welfare enhancing. Otherwise, it will be welfare reducing. ${ }^{43}$

\section{Overall Welfare Effect}

If the direct welfare effect of a cost-shifting policy is positive and the defendant is underdeterred, then a cost-shifting policy will be welfare improving. If the positive effect on access to justice is weak and the defendant is overdeterred, then this policy will reduce social welfare. Our analysis suggests that cost-shifting policies should be used with caution.

\section{Summary and Conclusions}

We provide the first theoretical analysis of legal disputes in a framework characterized by financially-constrained lawyers, third-party funding, and asymmetric information. To the best of our knowledge, our article is also the first to formally study the effects of public policies associated with legal disputes on access to justice by true victims.

We demonstrate that the lawyers' financial constraints permeate every decision made by the parties involves in a legal dispute. We show that the prevalent magnitude of the lawyers' financial constraints (the state of the world) determines the composition of the equilibrium mass of cases that are filed. In equilibrium, bargaining impasse occurs and access to justice is denied to some true victims. We present a formal analysis of two empirically-relevant policies: Cost-reducing and cost-shifting policies. We show that these policies might be welfare reducing if their positive effects on access to justice are weak and the potential injurers are overdeterred.

\footnotetext{
${ }^{43}$ When $\theta=0$, the direct effect will be unambiguously welfare reducing. Hence, a cost-shifting policy will be welfare reducing if the potential injurer is overdeterred (i.e., if the indirect effect is also welfare reducing). If the potential injurer is undeterred (i.e., if the indirect effect is welfare improving) and this indirect effect is strong enough, then a cost-shifting policy will be welfare improving.
} 
Our paper provides important policy implications. First, our work points to the significance of lawyers' financial constraints for the analysis of legal disputes. Second, our analysis underscores the importance of the care-taking and filing for the assessment of the welfare effects of public policies. In particular, we show that access to justice by true victims and deterrence are determinant factors of the overall social welfare effects of policies that relax lawyers' financial constraints. Importantly, our results inform current debate regarding the extension of cost-shifting policies by allowing lawyers to shift the financial costs of loans to their clients. Proponents of this reform have focused on the effects on access to justice. Our results suggest that a comprehensive assessment of these policies should also consider the effects on care-taking incentives for potential injurers.

In future work, we plan to extend our benchmark model to study the design of contracts between the lawyer and the third-party lender. In particular, the new framework will include the third-party lender as a fourth player and uncertainty about the likelihood of succeeding at trial. This environment will allow us to evaluate the effects of recourse and non-recourse loans, and the effects of uncertainty about the likelihood of succeeding at trial on access to justice for true victims, bargaining impasse, and care-taking incentives. These, and other extensions, remain fruitful areas for future research. 


\section{References}

Avraham, R. and Wickelgren, A.L. 2014. "Third-Party Litigation Funding: A Signaling Model." DePaul Law Review, pp. 233-264.

Bebchuk, L.A. 1984. "Litigation and Settlement under Imperfect Information." RAND Journal of Economics, pp. 404-415.

Bell, P.A. and O'Connell, J. 1997. Accidental Justice: The Dilemmas of Tort Law. Yale University Press.

Chang, H. 2000. "A Liberal Theory of Social Welfare." Yale Law Journal, pp. 173-235.

Daughety, A.F. and Reinganum, J. F. 2014. "The Effects of Third-Party Funding of Plaintiffs on Settlement." American Economic Review, pp. 2552-2566.

Daughety, A.F. and Reinganum, J. F. 2012. "Settlement." In Sachirico, C.W. (ed.), The Encyclopedia of Law and Economics. E. Elgar Publishing.

Deb, R., Pattanaik, P.K., and Razzolini, L. 1997. "Game Forms, Rights, and the Efficiency of Social Outcomes." Journal of Economy Theory, pp. 74-95.

Deffains, B. and Desrieux, C. Forthcoming. "To Litigate of Not to Litigate? The Impacts of Third-Party Financing on Litigation." International Review of Law and Economics.

Demougin, D. and Maultzsch, F. 2014. "Third-Party Financing of Litigation: Legal Approaches and a Formal Model." CESifo Economic Studies, pp. 525-553.

Diamond, P.A. 1967. "Cardinal Welfare, Individualistic Ethics, and Interpersonal Comparison of Utility: Comment." Journal of Political Economy, pp. 765-766.

Engstrom, N.F. 2014. "Lawyer Lending: Costs and Consequences." DePaul Law Review, pp. $377-446$

Garber, S. 2010. "Alternative Litigation Financing in the United States: Issues, Knowns, and Unknowns." RAND Institute for Civil Justice Law, Finance, and Capital Markets Program, Occasional Paper.

Gibbard, A. 1974. "A Pareto-Consistent Claim." Journal of Economic Theory, pp. 388-410.

Hillinger, C. and Lapham, V. 1971. "The Impossibility of a Paretian Liberal: Comment by Two Who Are Unreconstructed." Journal of Political Economy, pp. 1403-1405.

Hylton, K. 2012. "The Economics of Third-Party Financed Litigation." Journal of Law, Economics, and Policy, pp. 701-742.

Hylton, K. 2002. "An Asymmetric-Information Model of Litigation." International Review of Law and Economics, pp. 153-175.

Hylton, K. 1993. "Litigation Cost Allocation Rules and Compliance with the Negligence Standard." Journal of Legal Studies, 22, pp. 457-476.

Kaplow, L. and Shavell, S. 2002. Fairness versus Welfare. Harvard University Press.

Kaplow, L. and Shavell, S. 2001. "Any Non-Welfarist Method of Policy Assessment Violates the Pareto Principle." Journal of Political Economy, pp. 281-286. 
Kaplow, L. and Shavell, S. 1999. "The Conflict between Notions of Fairness and the Pareto Principle." American Law and Economics Review, pp. 63-77.

Kornhauser, L. 2015. "The Economic Analysis of Law." In Zalta, E.N. (ed.), Stanford Encyclopedia of Philosophy. http://plato.stanford.edu/archives/sum2015/entries/legaleconanalysis/.

Kornhauser, L. 2003. "Preference, Well-Being, and Morality in Social Decisions." Journal of Legal Studies, pp. 303-329.

Landeo, C.M. 2015. "Law and Economics and Tort Litigation Institutions: Theory and Experiments." In Zeiler, K. and Teitelbaum, J. (eds.), The Research Handbook on Behavioral Law and Economics. E. Elgar Publishing.

Landeo, C.M., Nikitin, M., and Babcock, L. 2007a. "Split-Awards and Disputes: An Experimental Study of a Strategic Model of Litigation." Journal of Economic Behavior and Organization, pp. 553-572.

Landeo, C.M., Nikitin, M., and Baker, S. 2007b. "Deterrence, Lawsuits and Litigation Outcomes under Court Errors." Journal of Law, Economics and Organization, pp. 5797.

Png, I.P.L. 1987. "Litigation, Liability, and the Incentives for Care." Journal of Public Economics, pp. 61-85.

Reinganum, J.F. and Wilde, L. 1986. "Settlement, Litigation, and the Allocation of Litigation Costs." RAND Journal of Economics, pp. 557-566.

Sen, A.K. 1971. "The Impossibility of a Paretian Liberal: A Reply." Journal of Political Economy, pp. 1406-1407.

Sen, A.K. 1970. "The Impossibility of a Paretian Liberal." Journal of Political Economy, pp. $152-157$.

Shavell, S. 1982. "Suit, Settlement, and Trial." Journal of Legal Studies, pp. 55-81.

Shepherd, J. 2014. "Uncovering the Silent Victims of the American Medical Liability System." Vanderbilt Law Review, pp. 151-195.

Spier, K.E. and Prescott, J.J. 2015. "Contracting on Litigation." Mimeo, Harvard Law School.

Spier, K.E. 1992. "The Dynamics of Pretrial Negotiation," Review of Economic Studies, pp. 93-108.

Trauner, M.T. 2009. "Personal Responsibility v. Corporate Liability: How Personal Injury Lawyers Screen Cases in an Era of Tort Reform." In Sandefur, R. (ed.), Sociology of Crime, Law and Deviance: Access to Justice. Bingley, UK: Emerald. 
[FOR ONLINE PUBLICATION]

\title{
FINANCIALLY-CONSTRAINED \\ LAWYERS: TECHNICAL APPENDICES
}

\author{
CLAUDIA M. LANDEO*and MAXIM NIKITIN ${ }^{\dagger}$
}

August 3, 2015

\section{INTRODUCTION}

This document presents the technical appendices for the paper "Financially-Constrained Lawyers." Two appendices are included: Appendix A, which presents the formal analysis of the benchmark model; and, Appendix B, which presents the formal analysis of the CostShifting Model.

The specific material included in both appendices is summarized below.

\section{Appendix A: Benchmark Model}

This appendix includes the following material.

- Main Material.

${ }^{*}$ University of Alberta, Department of Economics. Henry Marshall Tory Building 7-25, Edmonton, AB T6G 2H4, Canada. landeo@ualberta.ca; corresponding author.

${ }^{\dagger}$ International College of Economics and Finance, NRU HSE. Shabolovka 26, Moscow 119049, Russia. mnikitin@hse.ru. 
- Technical Conditions.

- Lemmas 1-4 and Proofs.

- Propositions 1-3 and Proofs.

- Additional Material.

- Equilibrium Outcomes and Payoffs.

- Effects of a Cost-Reducing Policy on Plaintiff's and Attorneys' Payoffs.

- Social Welfare Function

- Welfare Effects of a Cost-Reducing Policy

\section{Appendix B: Cost-Shifting Model}

This appendix includes the following material.

- Main Material

- Technical Conditions.

- Lemmas 6-7 and Proofs.

- Propositions 4-5 and Proofs.

- Additional Material.

- Equilibrium Outcomes and Payoffs.

- Effects of a Cost-Shifting Policy on Equilibrium Plaintiff's and Attorney's Payoffs. 


\section{APPENDIX A: BENCHMARK MODEL}

This appendix presents the formal analysis of the benchmark model.

\subsection{MAIN MATERIAL}

This section includes the technical conditions, the proofs of Lemmas 1-4, and the proofs of Propositions 1-3.

\subsubsection{TECHNICAL CONDITIONS}

The technical conditions used in the construction of the equilibrium follow. Equations (2), (3) and (4) were first presented in the main text of the paper. For convenience, we are reproducing these conditions here.

$$
\begin{gathered}
f_{F}<\gamma \tilde{A} . \\
\mu>\frac{\int_{\tilde{A}}^{\bar{A}}\left(A+C_{D}\right) g(A) d A}{\tilde{A}}-1 .
\end{gathered}
$$

There exists $\kappa>0$, such that for any $A \in(\tilde{A}, \bar{A})$,

$$
g(A)-C_{D} \frac{\partial g(A)}{\partial A}>\kappa
$$

\subsubsection{LEMMAS AND PROOFS}

Lemmas 1, 2, 3, and 4 and their proofs follow. Equations (5) and (6) were first presented in the main text of the paper.

LEMMA 1. The system of equations (5)-(6)

$$
\nu S+\int_{\tilde{A}}^{S} S g(A) d A+\int_{S}^{\bar{A}}\left(A+C_{D}\right) g(A) d A=\int_{\tilde{A}}^{\bar{A}}\left(A+C_{D}\right) g(A) d A
$$




$$
\nu+G(S)-G(\tilde{A})=C_{D} g(S)
$$

has a unique solution $(S, \nu)$ for a sufficiently large value of $\bar{A}$.

PROOF: Inserting equation (6) into (5) yields (after some algebra):

$$
\int_{\tilde{A}}^{S}\left(A+C_{D}-S\right) g(A) d A-S\left[C_{D} g(S)-G(S)+G(\tilde{A})\right]=0 .
$$

Denote the left-hand side of the equation as $\Phi(S)$, a function of $S$. The proof proceeds in several steps. We will show that $(1) \Phi(S)$ is continuous on the interval $[\tilde{A}, \bar{A}] ;(2) \frac{\partial \Phi(S)}{\partial S}>0$, i.e., the function $\Phi(S)$ is increasing in $S$ on the interval $[\tilde{A}, \bar{A}] ;(3) \Phi(\tilde{A})<0 ;(4) \Phi(\bar{A})>0$ for sufficiently large value of $\bar{A} ;(5) \Phi(S)=0$ has exactly one solution.

(1) Continuity of $\Phi(S)$ follows imediately from the assumptions about $G(A)$ and $g(A)$ functions.

(2) $\frac{\partial \Phi(S)}{\partial S}>0$.

Straightforward differentiation and further algebraic transformations yield:

$$
\frac{\partial \Phi(S)}{\partial S}=S\left[g(S)-C_{D} \frac{\partial g(S)}{\partial S}\right]>0 .
$$

The last inequality follows from condition (4).

(3) $\Phi(\tilde{A})<0$.

$$
\Phi(\tilde{A})=-\tilde{A} C_{D} g(\tilde{A})<0 .
$$

(4) $\Phi(\bar{A})>0$ for sufficiently large value of $\bar{A}$.

By condition (4) and the result obtained in step (2),

$$
\Phi(S)=\Phi(\tilde{A})+\int_{\tilde{A}}^{S} \frac{\partial \Phi(t)}{\partial t} d t \geq \Phi(\tilde{A})+\int_{\tilde{A}}^{S} \tilde{A} \kappa d t=\Phi(\tilde{A})+\tilde{A} \kappa(S-\tilde{A}) .
$$

The last expression is increasing in $S$ and is positive for $S>\frac{\kappa \tilde{A}^{2}-\Phi(\tilde{A})}{\kappa \tilde{A}}$. Hence, for $\bar{A}>$ $\frac{\kappa \tilde{A}^{2}-\Phi(\tilde{A})}{\kappa \tilde{A}}, \Phi(\bar{A})>0$. 
(5) In the previous stages, we showed that $\Phi(S)$ is a monotonic function with $\Phi(\tilde{A})<0$ and $\Phi(\bar{A})>0$. Hence, there exists a unique $S \in(\tilde{A}, \bar{A})$ such that $\Phi(S)=0$.

By equation (6), existence and uniqueness of $S$ implies existence and uniqueness of $\nu$.

LEMMA 2. The difference between the total mass of low-damage cases and the mass of lowand no-damage cases that are filed, $[G(\tilde{A})-\nu]$, is increasing in $\tilde{A}$.

\section{PROOF:}

Taking into account equation (6), total differentiation of equation (5) yields after some algebraic transformation:

$$
\frac{\partial \nu}{\partial \tilde{A}}=\frac{\left(S-\tilde{A}-C_{D}\right) g(\tilde{A})}{S}
$$

Hence,

$$
\frac{\partial[G(\tilde{A})-\nu]}{\partial \tilde{A}}=g(\tilde{A})-\frac{\partial \nu}{\partial \tilde{A}}=\frac{\left(\tilde{A}+C_{D}\right) g(\tilde{A})}{S}>0
$$

LEMMA 3. For any positive value of $l_{D}$, the function $L_{D}(\lambda)=K(\lambda)+\lambda l_{D}$ has a unique interior minimum, $\lambda_{D} \in(0,1)$, which is decreasing in $l_{D}$.

\section{PROOF:}

$$
\frac{\partial L_{D}(\lambda)}{\partial \lambda}=\frac{\partial K(\lambda)}{\partial \lambda}+l_{D}
$$

By the assumptions about the function $K(\lambda)$, the derivative of the total loss is continuous and monotonically increasing in $\lambda$, it is negative for sufficiently small values of $\lambda$, and it is positive for sufficiently large values of $\lambda$. Hence there exists a unique critical point, $\lambda_{D}$, such that $\frac{\partial L_{D}(\lambda)}{\partial \lambda}=0$, and $\lambda_{D}$ is the minimum point of $L_{D}(\lambda)$. 
Totally differentiating the first-order condition $\frac{\partial K(\lambda)}{\partial \lambda}+l_{D}=0$,

$$
\frac{\partial^{2} K(\lambda)}{\partial \lambda^{2}} d \lambda+d l_{D}=0
$$

Hence,

$$
\frac{\partial \lambda}{\partial l_{D}}=-\frac{1}{\frac{\partial^{2} K(\lambda)}{\partial \lambda^{2}}}<0 .
$$

An increase in $l_{D}$ reduces the optimal probability of accident, $\lambda_{D}$.

LEMMA 4. The No-Access to Justice component $\eta$ is increasing in $\tilde{A}$.

\section{PROOF:}

$$
\begin{gathered}
\eta=\left[\int_{0}^{\tilde{A}} g(A) d A-\nu\right]+\nu \beta . \\
\frac{\partial \eta}{\partial \tilde{A}}=g(\tilde{A})-\frac{\partial \nu}{\partial \tilde{A}}+\frac{\partial \nu}{\partial \tilde{A}} \beta+\frac{\partial \beta}{\partial \tilde{A}} \nu=g(\tilde{A})-\frac{\left(S-\tilde{A}-C_{D}\right)}{S} g(\tilde{A}) \frac{f_{M}}{\gamma S}+\frac{\partial \beta}{\partial \tilde{A}} \nu> \\
>g(\tilde{A})-g(\tilde{A})\left[1-\frac{\left(\tilde{A}+C_{D}\right)}{S}\right]+\frac{\partial \beta}{\partial \tilde{A}} \nu>0 .
\end{gathered}
$$

\subsubsection{PROPOSITIONS AND PROOFS}

PROPOSITION 1. Assume that conditions (2)-(4) hold. Then, the following strategy profile, together with the defendant's beliefs, characterize the perfect Bayesian equilibrium of the game.

Case 1: $G(\tilde{A})-\nu>0$

(1) The defendant chooses a probability of accident $\lambda_{D}=\arg \min \left\{K(\lambda)+\lambda \int_{\tilde{A}}^{\bar{A}}\left(A+C_{D}\right) g(A) d A\right\}$. If a lawsuit is filed, the defendant mixes between proposing a zero offer with probability $\beta=$ $1-\frac{f_{M}}{\gamma S}$ and proposing an offer $S>0$ with the complementary probability.

(2) A high-damage case is always filed by the plaintiff's attorney; an average low-damage case is filed with probability $\frac{\nu}{G(\tilde{A})}$; a no-damage case is never filed. 
(3) A high-damage plaintiff always rejects a zero offer and accepts an offer $S>0$ only if $A \leq S ;$ a low-damage plaintiff always accepts a non-negative offer; a no-damage plaintiff always accepts a non-negative offer.

(4) The defendant's equilibrium beliefs are as follows. When the defendant observes a lawsuit, he believes that $P(A=0)=0, P(0<A<\tilde{A})=\frac{\nu}{\nu+1-G(\tilde{A})}, P(\tilde{A} \leq A \leq y)=\frac{G(y)-G(\tilde{A})}{\nu+1-G(\tilde{A})}$ for any $y \in[\tilde{A}, \bar{A}]$.

Case 2: $G(\tilde{A})-\nu=0$

(1) The defendant chooses a probability of accident $\lambda_{D}=\arg \min \left\{K(\lambda)+\lambda \int_{\tilde{A}}^{\bar{A}}\left(A+C_{D}\right) g(A) d A\right\}$. If a lawsuit is filed, the defendant mixes between proposing a zero offer with probability $\beta \in$ $\left(1-\frac{f_{F}}{\gamma S}, 1-\frac{f_{M}}{\gamma S}\right)$ and proposing an offer $S>0$ with the complementary probability.

(2) A high-damage case is always filed by the plaintiff's attorney; a low-damage case is always filed; a no-damage case is never filed.

(3) A high-damage plaintiff always rejects a zero offer and accepts an offer $S>0$ only if $A \leq S ;$ a low-damage plaintiff always accepts a non-negative offer; a no-damage plaintiff always accepts a non-negative offer.

(4) The defendant's equilibrium beliefs are as follows. When the defendant observes a lawsuit, he believes that $P(A=0)=0, P(0<A \leq y)=G(y)$ for any $y \in(0, \bar{A}]$.

Case 3: $G(\tilde{A})-\nu<0$

(1) The defendant chooses a probability of accident $\lambda_{D}=\arg \min \left\{K(\lambda)+\lambda \int_{\tilde{A}}^{\bar{A}}\left(A+C_{D}\right) g(A) d A\right\}$. If the plaintiff files a lawsuit, the defendant mixes between proposing a zero offer with probability $\beta=1-\frac{f_{F}}{\gamma S}$ and proposing an offer $S>0$ with the complementary probability.

(2) A high-damage case is always filed by the plaintiff's attorney; a low-damage case is always filed; a no-damage case is filed with probability $\frac{\nu-G(\tilde{A})}{\mu}$.

(3) A high-damage plaintiff always rejects a zero offer and accepts an offer $S>0$ only if $A \leq S$; a low-damage case plaintiff always accepts a non-negative offer; a no-damage plaintiff always accepts a non-negative offer. 
(4) The defendant's equilibrium beliefs are as follows. When the defendant observes a lawsuit, he believes that $P(A=0)=\frac{\nu-G(\tilde{A})}{\nu+1-G(\tilde{A})}, P(0<A \leq y)=\frac{G(y)}{\nu+1-G(\tilde{A})}$ for any $y \in(0, \bar{A}]$.

PROOF: The proof consists of several steps.

Step 1. It is simple to show that offers lower than zero and greater than $\bar{A}$ are strictly dominated strategies. Offers $S \in(0, \tilde{A})$ are not in the set of equilibrium offers. Any offer in this range will be accepted by no-damage plaintiffs (losses equal to zero) and low-damage plaintiffs $(0<A<\tilde{A})$ and rejected by high-damage plaintiffs $(A \geq \tilde{A})$. Then, the defendant is better off by making a zero offer instead of making an offer $S \in(0, \tilde{A})$.

Step 2. A zero offer must be in the set of equilibrium offers, otherwise all non-meritorious cases (losses equal to zero) are filed. Suppose not. Then the defendant always offers at least $\tilde{A}$. Under condition (2), all non-meritorious cases are filed. The defendant will lose no less than $(1+\mu) \tilde{A}$, where $\mu$ is the measure of non-meritorious potential plaintiffs. Assuming $\mu$ is large enough(ensured by condition (3)), this loss (which is at least as large as $(1+\mu) \tilde{A}$ ) will be greater than the loss from offering $0, \int_{\tilde{A}}^{\bar{A}}\left(A+C_{D}\right) g(A) d A$.

Step 3. A zero offer cannot be the only offer. Suppose not, the defendant always offers 0. Then, only cases with types

$$
A \geq \hat{A} \equiv \frac{C_{P}+f_{M}+\left(C_{P}+f_{M}-x\right) r}{\gamma}
$$

will be filed. Attorneys with non-meritorious plaintiffs (losses equal to zero) and attorneys with plaintiffs of type $A \in(0, \hat{A})$ cannot file, as they expect a negative expected payoff. But then a zero offer is not the optimal offer. This is because the defendant can offer $\hat{A}+\epsilon$ and save litigation costs $C_{D}$ when facing a plaintiff of a type $\hat{A} \leq A \leq \hat{A}+\epsilon$. If $\epsilon<C_{D}$, the defendant's expected litigation loss will be $\int_{\hat{A}}^{\hat{A}+\epsilon}(\hat{A}+\epsilon) g(A) d A<\int_{\hat{A}}^{\hat{A}+\epsilon}\left(A+C_{D}\right) g(A) d A$. Hence, there is at least one positive offer $S$.

Step 4. There must be no-damage $(A=0)$ or low-damage cases $(0<A<\tilde{A})$ that are filed. Suppose not. Let $\check{A} \equiv \inf \min \left\{A_{\text {filed }}\right\}$, where $A_{\text {filed }}$ is the set of values of $A$ that are filed, where 
$\check{A} \geq \tilde{A}$. When the plaintiff of this type $A>\tilde{A}$ receives a zero offer, he is willing to proceed to trial, because his attorney's expected payoff from going to trial, $\gamma A-f_{M}-C_{P}-\left(C_{P}+f_{M}-x\right) r$ is greater than his payoff from not going to trial $-f_{M}$.

The possible cases are as follows.

(1) Type $\check{A}$ goes to trial with positive probability. Then, all $A>\check{A}$ go to trial if they do not get an offer $S \geq A$. This is why the zero offer is never accepted by any type. But then the zero offer is not an optimal offer: For a small positive $\epsilon$, the offer $\check{A}+\epsilon$ dominates the zero offer (the logic of Step 3 applies).

(2) Type $\check{A}$ never goes to trial. In any neighborhood of $\check{A}$ there exists $A_{1}>\check{A}$ such that $A_{1}$ is filed and the case proceeds to trial. Then all $A>A_{1}$ go to trial as well. As the neighborhood of $\check{A}$ can be infinitely small, all $A>\check{A}$ file and go to trial. This is why the zero offer is never accepted by any type $A>\check{A}$. But then the zero offer is not an optimal offer: For a small positive $\epsilon$, the offer $\tilde{A}+\epsilon$ dominates the offer of 0 (the logic of Step 3 applies).

Hence, $\nu>0$.

Step 5. Low-damage plaintiffs $(0<A<\tilde{A})$ should get a positive expected settlement offer $E(S)$ that makes their attorneys at least indifferent between filing and not filing. The plaintiff with $A<\tilde{A}$ always accepts the out-of-court settlement offer. If this is a zero offer, then the plaintiff drops the case. Otherwise, the plaintiff gets a positive out-of-court settlement compensation. The positive probability of getting a positive expected offer $E(S)$, defined as $(1-b)$ (the probability of getting a zero offer is defined as $b$ ), ensures a non-negative payoff net of filing cost for the attorney. Mathematically,

$$
\gamma[b \bullet 0+(1-b) E(S)]-f_{M} \geq 0 .
$$

Step 6. All high-damage cases $(A \geq \tilde{A})$ are filed.

For a high-damage case, the attorney's expected payoff at the filing stage is

$$
(1-b) \gamma E(S)+b\left[\gamma A-C_{P}-\left(C_{P}+f_{M}-x\right) r\right]-f_{M} .
$$


The last expression is non-negative for $A=\tilde{A}$ and strictly positive for $A>\tilde{A}$.

Step 7. We established that there are at least two offers, 0 and some $S \geq \tilde{A}$. This implies that the positive offer $S$ must minimize the expected loss of the defendant, and the defendant must be indifferent between offering 0 and $S$. This indifference condition is represented by equation (5):

$$
\nu S+\int_{\tilde{A}}^{S} S g(A) d A+\int_{S}^{\bar{A}}\left(A+C_{D}\right) g(A) d A=\int_{\tilde{A}}^{\bar{A}}\left(A+C_{D}\right) g(A) d A .
$$

The first-order optimality condition below indicates that the defendant minimizes the expected litigation loss with respect to $S$ over the interval $[\tilde{A}, \bar{A}]$, i.e., he takes into account that all plaintiffs with $A \geq \tilde{A}$ file (Step 6) and that $\nu>0$ (Step 4).

$$
\frac{\partial}{\partial S}\left[\nu S+\int_{0}^{S} S g(A) d A+\int_{S}^{\bar{A}}\left(A+C_{D}\right) g(A) d A\right]=0 .
$$

This last equation simplifies to equation (6)

$$
\nu+G(S)-G(\tilde{A})=C_{D} g(S) .
$$

Assuming that $\bar{A}$ is large enough (so that $\bar{A}>S$ ) and that the second-order optimality condition

$$
g(A)>C_{D} \frac{\partial g(A)}{\partial A}
$$

is satisfied for all $A \in[\tilde{A}, \bar{A}]$ (ensured by condition (4)), by Lemma 1, $S$ and $\nu$ are the unique equilibrium positive offer and equilibrium mass of no-damage and low-damage cases that are filed, respectively.

Step 8. The prevalent magnitude of the lawyers' financial constraints $\tilde{A}$ (the state of the world) determines one of three mutually-exclusive scenarios: $G(\tilde{A})-\nu>0, G(\tilde{A})-\nu=0$, and $G(\tilde{A})-\nu<0$. We call these three scenarios, Case 1, Case 2, and Case 3, respectively. Lemma 2 shows that a relaxation of the lawyers' financial constraints (i.e., a reduction in $\tilde{A}$ ) lowers $G(\tilde{A})-\nu$. If there exists $\tilde{A}^{*}$ such that $G\left(\tilde{A}^{*}\right)=\nu\left(\tilde{A}^{*}\right)($ Case 2$)$, then for $\tilde{A}>\tilde{A}^{*}, G(\tilde{A})>\nu$ (Case 1$)$ and for $\tilde{A}<\tilde{A}^{*}, G(\tilde{A})<\nu($ Case 3$)$. 
Step 9. Cases 1, 2, and 3 involve different compositions of equilibrium $\nu$, and hence, different compositions of the equilibrium mass of filed cases $\zeta$. Next, we analyze the composition of equilibrium $\nu$ and $\beta$ for Cases 1,2 , and 3 .

(1) Case 1: The equilibrium mass of low- and no-damage cases that are filed $\nu$ is lower than the total mass of low-damage cases $G(\tilde{A})$. In other words, the equilibrium mass of filed cases is composed by a subset of low-damage cases, in addition to all high-damage cases.

An attorney with a high-damage client is always willing to file a lawsuit (by Step 6). An attorney with an average low-damage client mixes between filing and not filing. ${ }^{1}$ Hence, he must be indifferent between these two strategies. The indifference condition

$$
f_{M}=\beta \bullet 0+(1-\beta) \gamma S
$$

yields $\beta$, the probability that the defendant makes a zero offer.

$$
\beta=1-\frac{f_{M}}{\gamma S}
$$

An attorney with a no-damage client never files a lawsuit because his expected payoff is negative.

$$
-f_{F}+\left(1-\frac{f_{M}}{\gamma S}\right) 0+\frac{f_{M}}{\gamma S} \gamma S=-f_{F}+f_{M}<0 .
$$

The mass of low-damage cases that are filed is $\nu$ and the total mass of low-damage cases is $G(\tilde{A})$. Hence, the probability of filing for an average low-damage case is $\frac{\nu}{G(\tilde{A})}$.

(2) Case 2: The equilibrium mass of low- and no-damage cases that are filed $\nu$ is equal to the total mass of low-damage cases $G(\tilde{A})$. In other words, the equilibrium mass of filed cases is composed by all low-damage cases, in addition to all high-damage cases.

An attorney with a high-damage case is always willing to file a lawsuit (by Step 6). An attorney with a low-damage client is always willing to file a lawsuit. An attorney with a no-damage client will never file a lawsuit. Mathematically,

$$
f_{M}<\beta \bullet 0+(1-\beta) \gamma S<f_{F},
$$

\footnotetext{
${ }^{1}$ In principle, the probability of filing for a low-damage plaintiff may depend on the specific $A$. Then, we use the expression "average low-damage client."
} 
which yields the range of values $\beta \in\left(1-\frac{f_{M}}{\gamma S}, 1-\frac{f_{F}}{\gamma S}\right)$.

(3) Case 3: The equilibrium mass of low- and no-damage cases that are filed $\nu$ is greater than the total mass of low-damage cases $G(\tilde{A})$. In other words, the equilibrium mass of filed cases is composed by all low-damage and a subset of no-damage cases, in addition to all high-damage cases.

An attorney with a high-damage client is always willing to file a lawsuit (by Step 6). An attorney with a low-damage client always files a lawsuit because his expected payoff is

$$
\left(1-\frac{f_{F}}{\gamma S}\right) \bullet 0+\frac{f_{F}}{\gamma S} \gamma S-f_{M}=f_{F}-f_{M}>0 .
$$

An attorney with a no-damage client must be indifferent between filing and not filing. The indifference condition

$$
f_{F}=\beta \bullet 0+(1-\beta) \gamma S
$$

yields $\beta$, the probability that the defendant makes a zero offer.

$$
\beta=1-\frac{f_{F}}{\gamma S}
$$

The mass of no-damage cases that are filed is $\nu-G(\tilde{A})$ and the total mass of no-damage cases is $\mu$. Hence, the probability of filing for a no-damage case is $\frac{\nu-G(\tilde{A})}{\mu}$.

Step 10. The equilibrium strategies of the average plaintiff and his attorney and the equilibrium mass of filed cases determine the beliefs of the defendant.

Case 1: All high-damage cases and a subset of low-damage cases are filed, and no-damage cases are not filed. The mass of high-damage cases that are filed is equal to the total mass of high-damage cases, $1-G(\tilde{A}) . \nu$ includes only the subset of low-damage cases that are filed. Therefore, the total mass of filed cases is $1-G(\tilde{A})+\nu$. As no-damage cases are not filed, the posterior (conditional on filing) probability of a no-damage case is 0 , the posterior probability of an average low-damage case is $\frac{\nu}{1-G(\tilde{A})+\nu}$, while the posterior probability of an average highdamage case is $\frac{1-G(\tilde{A})}{1-G(\tilde{A})+\nu}$. Given that all high-damage cases are filed and the distribution $G(A)$ is known by the defendant, he computes the posterior probability for any range of highdamage cases as the product of conditional probability for this particular range (conditional 
on a case being a high-damage case) and the posterior probability of a high-damage case. Mathematically, for any $y \in(\tilde{A}, \bar{A}]$,

$$
P(\tilde{A}<A \leq y \mid \text { Filing })=\frac{G(y)-G(\tilde{A})}{1-G(\tilde{A})} \frac{1-G(\tilde{A})}{1-G(\tilde{A})+\nu}=\frac{G(y)-G(\tilde{A})}{1-G(\tilde{A})+\nu} .
$$

Case 2: All high- and low-damage cases are filed, and no-damage cases are not filed. The mass of filed cases (low-damage and high-damage cases) equals 1. Therefore, the posterior (conditional on filing) distribution of types is described by the $\operatorname{cdf} G(A)$. Mathematically, for any $y \in(0, \bar{A}]$,

$$
P(0<A \leq y \mid \text { Filing })=G(y)
$$

Case 3: All high- and low-damage cases are filed, and $\nu-G(\tilde{A})$ of no-damage cases are filed. This is why the total mass of filed cases is $1-G(\tilde{A})+\nu$. Therefore, the posterior probability of a no-damage case is $\frac{\nu-G(\tilde{A})}{1-G(\tilde{A})+\nu}$, and the posterior probability of a meritorious case (highdamage or low-damage case) is $\frac{1}{1-G(\tilde{A})+\nu}$. Given that all meritorious cases are filed and the distribution $G(A)$ is known by the defendant, he computes the posterior probability for any range of meritorious cases as the product of conditional probability for this particular range (conditional on a case being a meritorious case) and the posterior probability of a meritorious case. Mathematically, for any $y \in(0, \bar{A}]$,

$$
P(\tilde{0}<A \leq y \mid \text { Filing })=G(y) \frac{1}{1-G(\tilde{A})+\nu}=\frac{G(y)}{1-G(\tilde{A})+\nu} .
$$

Step 11. Analyze the defendant's optimal level of care. Given the outcomes of the litigation and filing stages, the defendant's optimal probability of an accident $\lambda_{D}=\arg \min \left\{K(\lambda)+\lambda l_{D}\right\}=$ $\arg \min \left\{K(\lambda)+\lambda \int_{\tilde{A}}^{\bar{A}}\left(A+C_{D}\right) g(A) d A\right\}$. By Lemma 3 , for any positive value of $l_{D}$, the function $K(\lambda)+\lambda l_{D}$ has a unique interior minimum $\lambda_{D} \in(0,1)$.

PROPOSITION 2. A reduction in $\tilde{A}$ : (1) increases the expected litigation loss of the defendant $l_{D}$; (2) reduces the probability of an accident $\lambda_{D}$; (3) reduces the (strictly) positive out-of-court settlement offer $S$; (4) reduces the probability of a zero offer $\beta$; (5) increases the mass of filed cases $\zeta$; and (6) increases the probability of trial $\rho$ if $C_{D}<\tilde{A}$. 


\section{PROOF:}

(1) The expected litigation loss of the defendant is

$$
\begin{gathered}
l_{D}=\int_{\tilde{A}}^{\bar{A}}\left(A+C_{D}\right) g(A) d A \\
\frac{\partial l_{D}}{\partial \tilde{A}}=-\left(\tilde{A}+C_{D}\right) g(\tilde{A})<0 .
\end{gathered}
$$

This result applies to Cases 1 and 3, and across cases.

(2) By Lemma 3, an increase in the defendant's expected litigation loss, $l_{D}$, increases the spending on care and, therefore, reduces the probability of an accident. This result applies to Cases 1 and 3, and across cases.

(3) Total differentiating equations (1) and (2) yields (after some algebraic transformations):

$$
d \nu=d S\left[C_{D} \frac{\partial g(S)}{\partial S}-g(S)\right]
$$

and

$$
\left(S-\tilde{A}-C_{D}\right) g(\tilde{A}) d \tilde{A}=S d \nu
$$

From the last equation:

$$
\frac{\partial \nu}{\partial \tilde{A}}=\frac{\left(S-\tilde{A}-C_{D}\right) g(\tilde{A})}{S},
$$

and

$$
\frac{\partial S}{\partial \tilde{A}}=\frac{\left(\tilde{A}+C_{D}\right) g(\tilde{A})}{S\left[g(S)-C_{D} \frac{\partial g(S)}{\partial S}\right]} .
$$

By condition (4), the last expression is greater than zero. This result applies to Cases 1 and 3, and across cases.

(4) Consider Case 1. The probability of a zero offer is:

$$
\beta=1-\frac{f_{M}}{\gamma S}
$$


Therefore,

$$
\frac{\partial \beta_{1}}{\partial \tilde{A}}=\frac{f_{M}}{\gamma S^{2}} \frac{\partial S}{\partial \tilde{A}}>0
$$

In words, a reduction in $\tilde{A}$ reduces the probability of a zero offer $\beta$. The same logic applies to Case 3.

(5) Consider Case 1. Let $\zeta=\int_{\tilde{A}}^{\bar{A}} g(A) d A+\nu=1-G(\tilde{A})+\nu$ represent the aggregate filing. Hence,

$$
\frac{\partial \zeta}{\partial \tilde{A}}=-g(\tilde{A})+\frac{\partial \nu}{\partial \tilde{A}}=-\frac{\left(\tilde{A}+C_{D}\right) g(\tilde{A})}{S}<0 .
$$

In words, a reduction in $\tilde{A}$ increases filing. The same logic applies to Case 3 and across cases.

(6) Consider Case 1. The probability of trial (conditional on accident occurrence) is:

$$
\rho=\beta(1-G(\tilde{A}))+(1-\beta)(1-G(S))=1-G(\tilde{A})-\frac{f_{M}(G(S)-G(\tilde{A}))}{\gamma S} .
$$

Differentiating with respect to $\tilde{A}$ yields (after some algebraic manipulations):

$$
\frac{\partial \rho}{\partial \tilde{A}}=-g(\tilde{A})+\frac{\partial S}{\partial \tilde{A}} \frac{f_{M}}{\gamma} \frac{[G(S)-G(\tilde{A})-g(S) S]}{S^{2}}<0
$$

The last inequality holds because

$G(S)-G(\tilde{A})-g(S) S=C_{D} g(S)-\nu-g(S) S=\left(C_{D}-S\right) g(S)-\nu<\left(C_{D}-\tilde{A}\right) g(S)-\nu<0$, when $C_{D}<\tilde{A}$. The same logic applies to Case 3 and across cases.

PROPOSITION 3. If the defendant is under-deterred $\left(l_{W}>l_{D}\right)$ and $\theta>\underline{\theta}$, then the welfare effect of a cost-shifting policy is positive; if the defendant is over-deterred $\left(l_{W}<l_{D}\right)$ and $\theta<\underline{\theta}$, then the welfare effect of a cost-shifting policy is negative.

PROOF: The condition $l_{W}>l_{D}$ ensures that the indirect effect on social welfare is positive. The direct effect includes two negative terms $-\lambda_{D} \frac{\left(\tilde{A}+C_{D}\right) G(\tilde{A})}{S} f_{M}$ and $\lambda_{D}\left(C_{P}+C_{D}\right) \frac{\partial \rho}{\partial A}$ and one positive term $\lambda_{D} \theta \frac{\partial \eta}{\partial \bar{A}}$. The condition 


$$
\theta>\underline{\theta}=\frac{\lambda_{D} \frac{\left(\tilde{A}+C_{D}\right) G(\tilde{A})}{S} f_{M}-\lambda_{D}\left(C_{P}+C_{D}\right) \frac{\partial \rho}{\partial \tilde{A}}}{\lambda_{D} \frac{\partial \eta}{\partial \tilde{A}}}
$$

ensures that the direct effect on social welfare is positive. Hence the overall effect on social welfare is positive as well. The same logic applies to the second part of the proposition. 


\subsection{ADDITIONAL MATERIAL}

This section includes the analysis of equilibrium outcomes and payoffs, the analysis of the effects of a cost-reducing policy on plaintiff's and attorneys' payoffs, and the welfare analysis of a cost-reducing policy.

\subsubsection{EQUILIBRIUM OUTCOMES AND PAYOFFS}

The equilibrium outcomes and payoffs for Cases 1, 2, and 3 are as follows.

\section{CASE 1}

The equilibrium outcomes and payoffs are as follows.

(1) Mass of filed cases (conditional on accident occurrence):

$$
\zeta=\int_{\tilde{A}}^{\bar{A}} g(A) d A+\nu
$$

(2) Probability of trial (conditional on accident occurrence and filing):

$$
\rho=\beta[1-G(\tilde{A})]+(1-\beta)[1-G(S)]=1-G(\tilde{A})-\frac{f_{M}[G(S)-G(\tilde{A})]}{\gamma S} .
$$

(3) Defendant's expected litigation loss (conditional on accident occurrence and filing):

$$
l_{D}=\int_{\tilde{A}}^{\bar{A}}\left(A+C_{D}\right) g(A) d A .
$$

(4) Plaintiff's expected payoff (conditional on accident occurrence and filing).

(4.1) Low-damage plaintiff $(0<A<\tilde{A})$ :

$$
\Pi_{P}=(1-\beta) S(1-\gamma)+\beta \bullet 0=\frac{f_{M}(1-\gamma)}{\gamma} .
$$

(4.2) High-damage plaintiff of type $A \in[\tilde{A}, S)$ : 


$$
\Pi_{P}=\beta(1-\gamma) A+(1-\beta)(1-\gamma) S=\left[\left(1-\frac{f_{M}}{\gamma S}\right)(1-\gamma) A+\frac{f_{M}(1-\gamma)}{\gamma}\right]
$$

(4.3) High-damage plaintiff of type $A \in[S, \bar{A}]$ :

$$
\Pi_{P}=(1-\gamma) A
$$

(4.4) Average expected payoff (aggregating across plaintiff's types):

$$
\frac{\frac{f_{M}(1-\gamma)}{\gamma}[G(S)-G(\tilde{A})+\nu]+\int_{\tilde{A}}^{S} \beta(1-\gamma) A g(A) d A+\int_{S}^{\bar{A}}(1-\gamma) A g(A) d A}{1-G(\tilde{A})+\nu}
$$

(5) Attorney's expected payoff (conditional on accident occurrence and filing).

(5.1) Attorney with low-damage client $(0<A<\tilde{A})$ :

$$
\Pi_{P A}=\beta \bullet 0+(1-\beta) \gamma S-f_{M}=f_{M}-f_{M}=0 .
$$

(5.2) Attorney with high-damage client of type $A \in[\tilde{A}, S)$ :

$\Pi_{P A}=\beta\left[\gamma A-C_{P}-\left(C_{P}+f_{M}-x\right) r\right]+(1-\beta) \gamma S-f_{M}=\beta\left[\gamma A-C_{P}-\left(C_{P}+f_{M}-x\right) r\right]-f_{M}$.

(5.3) Attorney with high-damage client of type $A \in[S, \bar{A}]$ :

$$
\Pi_{P A}=\left[\gamma A-C_{P}-\left(C_{P}+f_{M}-x\right) r\right]-f_{M}
$$

(5.4) Average expected payoff (aggregating across plaintiff's types):

$$
\begin{gathered}
\frac{\int_{\tilde{A}}^{S}\left(1-\frac{f_{M}}{\gamma S}\right)\left[\gamma A-C_{P}-\left(C_{P}+f_{M}-x\right) r\right] g(A) d A}{1-G(\tilde{A})+\nu}+ \\
+\frac{\int_{S}^{\bar{A}}\left[\gamma A-C_{P}-\left(C_{P}+f_{M}-x\right) r\right] g(A) d A}{1-G(\tilde{A})+\nu}-f_{M} .
\end{gathered}
$$




\section{CASE 2}

The equilibrium outcomes and payoffs are as follows.

(1) Mass of filed cases (conditional on accident occurrence):

$$
\zeta=\int_{\tilde{A}}^{\bar{A}} g(A) d A+\nu
$$

(2) Probability of trial (conditional on accident occurrence and filing):

$$
\rho=\beta[1-G(\tilde{A})]+(1-\beta)[1-G(S)] .
$$

(3) Defendant's expected litigation loss (conditional on accident occurrence and filing):

$$
l_{D}=\int_{\tilde{A}}^{\bar{A}}\left(A+C_{D}\right) g(A) d A .
$$

(4) Plaintiff's expected payoff (conditional on accident occurrence and filing).

(4.1) Low-damage plaintiff $(0<A<\tilde{A})$ :

$$
\Pi_{P}=(1-\beta) S(1-\gamma)+\beta \bullet 0 .
$$

(4.2) High-damage plaintiff of type $A \in[\tilde{A}, S)$ :

$$
\Pi_{P}=\beta(1-\gamma) A+(1-\beta)(1-\gamma) S .
$$

(4.3) High-damage plaintiff of type $A \in[S, \bar{A}]$ :

$$
\Pi_{P}=(1-\gamma) A
$$

(4.4) Average expected payoff (aggregating across plaintiff's types):

$$
(1-\beta)(1-\gamma) S G(S)+\int_{\tilde{A}}^{S} \beta(1-\gamma) A g(A) d A+\int_{S}^{\bar{A}}(1-\gamma) A g(A) d A .
$$


(5) Attorney's expected payoff (conditional on accident occurrence and filing).

(5.1) Attorney with low-damage client $(0<A<\tilde{A})$ :

$$
\Pi_{P A}=\beta \bullet 0+(1-\beta) \gamma S-f_{M}=(1-\beta) \gamma S-f_{M}
$$

(5.2) Attorney with high-damage client of type $A \in[\tilde{A}, S)$ :

$$
\Pi_{P A}=\beta\left(\gamma A-C_{P}-\left(C_{P}+f_{M}-x\right) r\right)+(1-\beta) \gamma S-f_{M}
$$

(5.3) Attorney with high-damage client of type $A \in[S, \bar{A}]$ :

$$
\Pi_{P A}=\left[\gamma A-C_{P}-\left(C_{P}+f_{M}-x\right) r\right]-f_{M} .
$$

(5.4) Average expected payoff (aggregating across plaintiff's types):

$$
\begin{gathered}
(1-\beta) \gamma S G(S)+\int_{\tilde{A}}^{S} \beta\left[\gamma A-C_{P}-\left(C_{P}+f_{M}-x\right) r\right] g(A) d A+ \\
+\int_{S}^{\bar{A}}\left[\gamma A-C_{P}-\left(C_{P}+f_{M}-x\right) r\right] g(A) d A-f_{M}
\end{gathered}
$$

\section{CASE 3}

The equilibrium outcomes and payoffs are as follows.

(1) Mass of filed cases (conditional on accident occurrence):

$$
\zeta=\int_{\tilde{A}}^{\bar{A}} g(A) d A+\nu
$$

(2) Probability of trial (conditional on accident occurrence and filing):

$$
\rho=\beta[1-G(\tilde{A})]+(1-\beta)[1-G(S)]=1-G(\tilde{A})-\frac{f_{F}[G(S)-G(\tilde{A})]}{\gamma S} .
$$


(3) Defendant's expected litigation loss (conditional on accident occurrence and filing):

$$
l_{D}=\int_{\tilde{A}}^{\bar{A}}\left(A+C_{D}\right) g(A) d A
$$

(4) Plaintiff's expected payoff (conditional on accident occurrence and filing).

(4.1) Non-damage plaintiff $(A=0)$ :

$$
\Pi_{P}=\beta \bullet 0+(1-\beta)(1-\gamma) S=\frac{f_{F}(1-\gamma)}{\gamma} .
$$

(4.2) Low-damage plaintiff $(0<A<\tilde{A})$ :

$$
\Pi_{P}=\beta \bullet 0+(1-\beta)(1-\gamma) S=\frac{f_{F}(1-\gamma)}{\gamma} .
$$

(4.3) High-damage plaintiff of type $A \in[\tilde{A}, S]$ :

$$
\Pi_{P}=\beta(1-\gamma) A+(1-\beta)(1-\gamma) S=\left[\left(1-\frac{f_{F}}{\gamma S}\right)(1-\gamma) A+\frac{f_{F}(1-\gamma)}{\gamma}\right] .
$$

(4.4) High-damage plaintiff of type $A \in[S, \bar{A}]$ :

$$
\Pi_{P}=(1-\gamma) A
$$

(4.5) Average expected payoff (aggregating across plaintiff's types):

$$
\frac{\frac{f_{F}(1-\gamma)}{\gamma}[G(S)-G(\tilde{A})+\nu]+\int_{\tilde{A}}^{S} \beta(1-\gamma) A g(A) d A+\int_{S}^{\bar{A}}(1-\gamma) A g(A) d A}{1-G(\tilde{A})+\nu} .
$$

(5) Attorney's expected payoff (conditional on accident occurrence and filing).

(5.1) Attorney with no-damage client $(A=0)$ :

$$
\Pi_{P A}=\beta \bullet 0+(1-\beta) \gamma S-f_{F}=0 .
$$

(5.2) Attorney with low-damage client $(0<A<\tilde{A})$ : 


$$
\Pi_{P A}=\beta \bullet 0+(1-\beta) \gamma S-f_{M}=f_{F}-f_{M}
$$

(5.3) Attorney with high-damage client of type $A \in[\tilde{A}, S]$ :

$\Pi_{P A}=\beta\left[\gamma A-C_{P}-\left(C_{P}+f_{M}-x\right) r\right]+(1-\beta) \gamma S-f_{M}=\beta\left[\gamma A-C_{P}-\left(C_{P}+f_{M}-x\right) r\right]+\left(f_{F}-f_{M}\right)$.

(5.4) Attorney with high-damage client of type $A \in[S, \bar{A}]$ :

$$
\Pi_{P A}=\left[\gamma A-C_{P}-\left(C_{P}+f_{M}-x\right) r\right]-f_{M}
$$

(5.5) Average expected payoff (aggregating across plaintiff's types) is:

$$
\begin{gathered}
\frac{[G(S)-G(\tilde{A})+\nu] f_{F}+\int_{\tilde{A}}^{S} \beta\left[\gamma A-C_{P}-\left(C_{P}+f_{M}-x\right) r\right] g(A) d A}{1-G(\tilde{A})+\nu}+ \\
+\frac{\int_{S}^{\bar{A}}\left[\gamma A-C_{P}-\left(C_{P}+f_{M}-x\right) r\right] g(A) d A}{1-G(\tilde{A})+\nu}-f_{M} .
\end{gathered}
$$

\subsubsection{EFFECTS OF A COST-REDUCING POLICY ON PAYOFFS}

This section presents the effects of a cost-reducing policy on the plaintiff's and attorney's payoffs for Case 1 .

\section{EFFECTS ON THE PLAINTIFF'S PAYOFF}

The average expected payoff for the plaintiffs (aggregating across plaintiff's types) is

$$
\frac{\frac{f_{F}(1-\gamma)}{\gamma}[G(S)-G(\tilde{A})+\nu]+\int_{\tilde{A}}^{S} \beta(1-\gamma) A g(A) d A+\int_{S}^{\bar{A}}(1-\gamma) A g(A) d A}{1-G(\tilde{A})+\nu} .
$$

The impact of a reduction in $\tilde{A}$ on the average expected payoff for the plaintiff is generally ambiguous. As we will show below, the effect depends on the value of $A$ relative to the old and new thresholds and the old and new equilibrium offers. 
Let $\tilde{A}^{\prime}<\tilde{A}, S^{\prime}<S$, and $\beta^{\prime}<\beta$ denote the new threshold, the new equilibrium offer and the new probability of a zero offer, respectively. Let $\Pi_{P}$ and $\Pi_{P}^{\prime}$ denote the old and new plaintiff's expected payoff, respectively. We analyze the effects of a cost-reducing policy on the plaintiff's payoff by classifying the cases into five different categories. The first and second inequalities refer to the old and new position of $A$, respectively.

(1) $0<A<\tilde{A}$ and $0<A<\tilde{A}^{\prime}$ : The plaintiff is not affected. Regardless of the change, the case does not proceed to trial. Due to asymmetric information, the plaintiff receives a strictly positive offer with a strictly positive probability. The reduction in the positive offer due to the policy is offset by the increase in the probability that the defendant makes a strictly positive offer.

$$
\Pi_{P}=(1-\gamma)[\beta \bullet 0+(1-\beta) S]=\frac{(1-\gamma) f_{M}}{\gamma}=(1-\gamma)\left[\beta^{\prime} \bullet 0+\left(1-\beta^{\prime}\right) S^{\prime}\right]=\Pi_{P}^{\prime}
$$

(2) $0<A<\tilde{A}$ and $A>\tilde{A}^{\prime}$ : The plaintiff is better off. After receiving a zero offer, the plaintiff does not need to drop the case (and get a zero payoff). He can now go to trial and get a strictly positive payoff.

$$
\begin{gathered}
\Pi_{P}=(1-\gamma)[\beta \bullet 0+(1-\beta) S]=\frac{(1-\gamma) f_{M}}{\gamma}< \\
<(1-\gamma)\left(\beta^{\prime} A+\frac{f_{M}}{\gamma}\right)=(1-\gamma)\left[\beta^{\prime} A+\left(1-\beta^{\prime}\right) S^{\prime}\right]=\Pi_{P}^{\prime} .
\end{gathered}
$$

(3) $\tilde{A}<A<S$ and $\tilde{A}^{\prime}<A<S^{\prime}$ : The plaintiff is worse off. The positive effect of an increase in the probability of a strictly positive offer less than offsets the negative effect of a reduction in the strictly positive offer.

$$
\begin{gathered}
\Pi_{P}=(1-\gamma)[\beta A+(1-\beta) S]=(1-\gamma)\left[\left(1-\frac{f_{M}}{\gamma S}\right) A+\frac{f_{M}}{\gamma S} S\right]> \\
>(1-\gamma)\left[\left(1-\frac{f_{M}}{\gamma S^{\prime}}\right) A+\frac{f_{M}}{\gamma S^{\prime}} S^{\prime}\right]=(1-\gamma)\left[\beta^{\prime} A+\left(1-\beta^{\prime}\right) S^{\prime}\right]=\Pi_{P}^{\prime} .
\end{gathered}
$$

(4) $\tilde{A}<A<S$ and $A>S^{\prime}$ : The plaintiff is worse off. The case now proceeds to trial with certainty, and an award equal to $A$ is granted to the plaintiff. Then, a generous expected payoff (due to a settlement offer greater than $A$ ) is now replaced with a lower payoff.

$$
\Pi_{P}=(1-\gamma)[\beta A+(1-\beta) S]>(1-\gamma) A=\Pi_{P}^{\prime}
$$


(5) $A>S$ and $A>S^{\prime}$ : The plaintiff is not affected. Regardless of the change, the case proceeds to trial and the plaintiff's payoff is $\Pi_{P}=(1-\gamma) A=\Pi_{P}^{\prime}$.

\section{EFFECTS ON THE ATTORNEY'S PAYOFF}

The average expected payoff for the plaintiff's attorney (aggregating across plaintiff's types) is

$$
\begin{gathered}
\frac{\int_{\tilde{A}}^{S}\left(1-\frac{f_{M}}{\gamma S}\right)\left\{\gamma A-\left[C_{P}+\left(C_{P}+f_{M}-x\right) r\right]\right\} g(A) d A}{1-G(\tilde{A})+\nu}+ \\
+\frac{\int_{S}^{\bar{A}}\left\{\gamma A-\left[C_{P}+\left(C_{P}+f_{M}-x\right) r\right]\right\} g(A) d A}{1-G(\tilde{A})+\nu}-f_{M} .
\end{gathered}
$$

The attorney's expected payoff depends directly on $C_{P}, f_{M}$, and $r$, which also affect $\tilde{A}$. Then, only an evaluation of the effects of individual factors can be implemented.

Consider a reduction in the lawyer's financial cost $r$. Its impact on the average expected payoff for the plaintiff's attorney is generally ambiguous. Two effects arise: An indirect negative effect of a reduction in $r$ on the likelihood of trial (and hence, on the litigation costs $C_{P}$ ), which operates through a reduction in $\tilde{A}$; and, a direct positive effect of a reduction in $r$. The indirect negative effect might be partly or fully offset by the direct positive effect. We will show that the impact of a reduction in $r$ depends on the value of $A$ relative to the old and new thresholds and the old and new equilibrium offers.

Let $\tilde{A}^{\prime}<\tilde{A}, S^{\prime}<S, \beta^{\prime}<\beta$, and $r^{\prime}<r$ denote the new threshold, the new equilibrium offer, the new probability of proposing a zero offer, and the new lawyers' financial cost, respectively. Let $\Pi_{P A}$ and $\Pi_{P A}^{\prime}$ denote the old and new attorney's expected payoff, respectively. We will analyze the effect of a reduction in $r$ by classifying the cases into five different categories. The first and second inequalities denote the old and new position of $A$, respectively.

(1) $0<A<\tilde{A}$ and $0<A<\tilde{A}^{\prime}$ : The attorney is not affected. Regardless of the change, the case does not proceed to trial. His old and new expected payoffs are $\Pi_{P A}=\gamma[\beta \bullet 0+(1-$ $\beta) S]-f_{M}=f_{m}-f_{M}=0$ and $\Pi_{P A}^{\prime}=\gamma\left[\beta^{\prime} \bullet 0+\left(1-\beta^{\prime}\right) S^{\prime}\right]-f_{M}=f_{M}-f_{M}=0$, respectively.

(2) $0<A<\tilde{A}$ and $A>\tilde{A}^{\prime}$ : The attorney is better off. The case can proceed to trial now; before the policy, the case was dropped. His old and new expected payoffs are $\Pi_{P A}=$ 
$\gamma\left[\beta \bullet 0+(1-\beta) S^{*}\right]-f_{M}=f_{M}-f_{M}=0$ and $\Pi_{P A}^{\prime}=f_{M}+\gamma \beta^{\prime} A-\beta^{\prime}\left[C_{P}+\left(f_{M}-C_{P}-x\right) r^{\prime}\right]-f_{M}>0$, respectively.

(3) $\tilde{A}<A<S$ and $\tilde{A}^{\prime}<A<S^{\prime}$ : The effect is ambiguous because the indirect negative impact of the policy through a reduction in $\beta$ is fully or partially offset by the direct positive effect. His old and new expected payoffs are $\Pi_{P A}=f_{M}+\gamma \beta A-\beta\left[C_{P}+\left(f_{M}-C_{P}-x\right) r\right]-f_{M}$ and $\Pi_{P A}^{\prime}=f_{M}+\gamma \beta^{\prime} A-\beta^{\prime}\left[C_{P}+\left(f_{M}-C_{P}-x\right) r^{\prime}\right]-f_{M}$, respectively.

(4) $\tilde{A}<A<S$ and $A>S^{\prime}$ : The effect is ambiguous. The impact of a lower $r$ might be partially or fully offset by the higher litigation costs (after the policy, the case always goes to trial; before the policy, out-of-court settlement was possible). His old and new expected payoffs are $\Pi_{P A}=f_{M}+\gamma \beta A-\beta\left[C_{P}+\left(f_{M}+C_{P}-x\right) r\right]-f_{M}$ and $\Pi_{P A}^{\prime}=\gamma A-\left[C_{P}+\left(f_{M}+C_{P}-x\right) r^{\prime}\right]-f_{M}$, respectively.

(5) $A>S$ and $A>S^{\prime}$ : The attorney is better off. His initial expected payoff $\Pi_{P A}=$ $\gamma A-\left[C_{P}+\left(f_{M}+C_{P}-x\right) r\right]-f_{M}$ increases due to the direct effect of a reduction in the financial cost $r$.

\subsubsection{SOCIAL WELFARE FUNCTION}

Let $\Pi(A) \equiv \Pi_{P}(A)+\Pi_{D}(A)+\Pi_{P A}(A)+\Pi_{F}(A)$ be the sum of expected payoffs for the plaintiff, the defendant, the plaintiff's attorney, and the third-party funder when the plaintiff's type is $A$. Let $(1-\eta)$ be the mass of true victims who get access to justice.

DEFINITION 7. The social welfare function $S W$, evaluated at $\lambda_{D}$, is defined as follows.

$$
\begin{gathered}
S W=-K\left(\lambda_{D}\right)-\lambda_{D} \int_{0}^{\bar{A}} A g(A) d A+\lambda_{D} \int_{0}^{\bar{A}} \Pi(A) g(A) d A+\lambda_{D}[\theta(1-\eta)]= \\
=-K\left(\lambda_{D}\right)-\lambda_{D} \int_{0}^{\bar{A}} A g(A) d A+\lambda_{D} \int_{0}^{\bar{A}}\left[\Pi_{P}(A)+\Pi_{D}(A)+\Pi_{P A}(A)+\Pi_{F}(A)\right] g(A) d A+ \\
+\lambda_{D}[\theta(1-\eta)] .
\end{gathered}
$$

The expression $\int_{0}^{\bar{A}} \Pi(A) g(A) d A$ can be simplified as follows. Consider three cases. 
Case 1: $A \geq S$

$\Pi(A)=(1-\gamma) A+\left[\gamma A-f_{M}-C_{P}-\left(f_{M}+C_{P}-x\right) r\right]-\left(A+C_{D}\right)+\left(f_{M}+C_{P}-x\right) r=-f_{M}-C_{P}-C_{D}$.

Hence,

$$
\int_{S}^{\bar{A}} \Pi(A) g(A) d A=(1-G(S))\left[-f_{M}-C_{P}-C_{D}\right]
$$

Case 2: $\tilde{A} \leq A<S$

$$
\begin{gathered}
\Pi(A)=[(1-\beta)(1-\gamma) S+\beta(1-\gamma) A]+\left[-f_{M}+(1-\beta) \gamma S+\beta\left(\gamma A-C_{P}-\left(f_{M}+C_{P}-x\right) r\right)\right]+ \\
+\left[-\beta\left(A+C_{D}\right)-(1-\beta) S\right]+\left[\left(f_{M}+C_{P}-x\right) r\right]=-f_{M}-\beta\left(C_{P}+C_{D}\right) .
\end{gathered}
$$

Hence,

$$
\int_{\tilde{A}}^{S} \Pi(A) g(A) d A=[G(S)-G(A)]\left[-f_{M}-\beta\left(C_{P}+C_{D}\right)\right] .
$$

Case 3: $0<A<\tilde{A}$

A mass $\nu$ of low-damage cases are filed, and a mass $[1-G(\tilde{A})-\nu]$ of low-damage cases are not filed. ${ }^{2}$ If the lawyer with a client of type $A$ does not file a lawsuit, then the expected payoffs for the four players is zero. Hence, $\Pi(A)=0$. If the lawyer with a client of type $A$ files a lawsuit, then

$$
\Pi(A)=[(1-\beta)(1-\gamma) S]+\left[-f_{M}+(1-\beta) \gamma S\right]+[-(1-\beta) S]+0=-f_{M} .
$$

Aggregating across types $A \in(0, \tilde{A})$ :

$$
\int_{0}^{\tilde{A}} \Pi(A) g(A) d A=-f_{M} \bullet \nu .
$$

Aggregating across all the types:

$$
\int_{0}^{\bar{A}} \Pi(A) g(A) d A=-[1-G(\tilde{A})+\nu] f_{M}-\{[1-G(S)]+\beta[G(S)-G(\tilde{A})]\}\left(C_{P}+C_{D}\right)=-\zeta f_{M}-\rho\left(C_{P}+C_{D}\right) .
$$

Then,

$$
S W=-K\left(\lambda_{D}\right)-\lambda_{D}\left[\int_{0}^{\bar{A}} A g(A) d A+\zeta f_{M}+\rho\left(C_{P}+C_{D}\right)\right]+\lambda_{D} \theta(1-\eta) .
$$

\footnotetext{
${ }^{2}$ Remember that this analysis corresponds to the equilibrium for Case 1.
} 


\section{SOCIAL WELFARE FUNCTION AND VALUES OF $\theta$}

Case 1: $\theta=0$

$$
S W=-K\left(\lambda_{D}\right)-\lambda_{D}\left[\int_{0}^{\bar{A}} A g(A) d A+\zeta f_{M}+\rho\left(C_{P}+C_{D}\right)\right] .
$$

The social welfare function $S W$ encompasses the sum of the net expected payoffs for all players.

Case 2: $\theta>0$

$$
S W=-K\left(\lambda_{D}\right)-\lambda_{D}\left[\int_{0}^{\bar{A}} A g(A) d A+\zeta f_{M}+\rho\left(C_{P}+C_{D}\right)\right]+\lambda_{D} \theta(1-\eta) .
$$

The social welfare function $S W$ also accounts for the social value of preserving citizens' rights to get access to justice.

\section{SOCIAL WELFARE FUNCTION AND SOCIAL WELFARE LOSS FUNCTION}

Case 1: $\theta=0$

The maximization of the social welfare function $S W$

$$
S W=-K\left(\lambda_{D}\right)-\lambda_{D}\left[\int_{0}^{\bar{A}} A g(A) d A+\zeta f_{M}+\rho\left(C_{P}+C_{D}\right)\right]
$$

is equivalent to the minimization of the social welfare loss function $S W L$ :

$$
S W L=K\left(\lambda_{D}\right)+\lambda_{D}\left[\int_{0}^{\bar{A}} A g(A) d A+\zeta f_{M}+\rho\left(C_{P}+C_{D}\right)\right] .
$$

Case 2: $\theta>0$

The maximization of the social welfare function $S W$

$$
S W=-K\left(\lambda_{D}\right)-\lambda_{D}\left[\int_{0}^{\bar{A}} A g(A) d A+\zeta f_{M}+\rho\left(C_{P}+C_{D}\right)\right]+\lambda_{D} \theta(1-\eta)
$$

is equivalent to the minimization of the social welfare loss function $S W L$ :

$$
S W L=K\left(\lambda_{D}\right)+\lambda_{D}\left[\int_{0}^{\bar{A}} A g(A) d A+\zeta f_{M}+\rho\left(C_{P}+C_{D}\right)\right]+\lambda_{D} \theta \eta .
$$




\subsubsection{WELFARE EFFECTS OF A COST-REDUCING POLICY}

This section presents the welfare definitions for Cases 2-3, and the analysis of the effects of a cost-reducing policy on social welfare for Case $3 .^{3}$

\section{DEFINITIONS}

Consider the "No-Access to Justice" component $\eta$ in Cases 2 and 3. Given Definition 2,

$$
\eta=\beta \int_{0}^{\tilde{A}} g(A) d A .
$$

Intuitively, in Cases 2 and 3, all high-damage and low-damage cases are filed. Then, the $\eta$ term only includes the low-damage plaintiffs who file a lawsuit but receive a zero offer, and hence, need to drop their cases. ${ }^{4}$

The total filing costs (TotalFilingCosts) are equal to $f_{M}$ and $f_{M}+\left[\nu-G(\tilde{A}] f_{F}\right.$, for Cases 2 and 3 , respectively.

DEFINITION 8. The social loss from litigation $l_{W}$ is defined as follows.

$$
\begin{gathered}
l_{W}=\int_{0}^{\bar{A}} A g(A) d A+\text { TotalFilingCosts }+\rho \bullet\left(C_{P}+C_{D}\right)+\theta \eta= \\
=\int_{0}^{\bar{A}} A g(A) d A+f_{M}+[\nu-G(\tilde{A})] f_{F}+\left[\beta \int_{\tilde{A}}^{\bar{A}} g(A) d A+(1-\beta) \int_{S}^{\bar{A}} g(A) d A\right]\left(C_{P}+C_{D}\right)+\theta G(\tilde{A}) \beta .
\end{gathered}
$$

The social loss from litigation $l_{W}$ encompasses four main components: (1) total social harm from an accident $\int_{0}^{\bar{A}} A g(A) d A$; (2) total filing cost $f_{M}$; (4) total legal costs incurred in case of trial $\left(C_{P}+C_{D}\right)$; and, (4) social cost associated with the inability of true victims to get access to justice, "No Access to Justice" term $(\eta)$.

DEFINITION 9. The social welfare loss $S W L$ is defined as follows.

${ }^{3}$ Case 2 is a borderline case. Any change in $\tilde{A}$ will shift the equilibrium from Case 2 to Case 1 or to Case 3.

${ }^{4}$ In other words, in Cases 2 and 3, the first term stated in Definition 2 is an empty set. 


$$
\begin{gathered}
S W L=K\left(\lambda_{D}\right)+\lambda_{D} l_{W}= \\
=K\left(\lambda_{D}\right)+\lambda_{D}\left[\int_{0}^{\bar{A}} A g(A) d A+\text { TotalFilingCosts }+\rho \bullet\left(C_{P}+C_{D}\right)+\theta \eta\right] \\
=K\left(\lambda_{D}\right)+\lambda_{D}\left\{\int_{0}^{\bar{A}} A g(A) d A+\left[f_{M}+(\nu-G(\tilde{A})) f_{F}\right]+\right. \\
+\left[\beta \int_{\tilde{A}}^{\bar{A}} g(A) d A+(1-\beta) \int_{S}^{\bar{A}} g(A) d A\right]\left(C_{P}+C_{D}\right)+ \\
\left.+\theta \int_{0}^{\tilde{A}} g(A) d A\left(1-\frac{f_{F}}{\gamma S}\right)\right\} .
\end{gathered}
$$

\section{SOCIAL WELFARE ANALYSIS}

LEMMA 5. For Case 3, the No-Access to Justice component $\eta$ is increasing in $\tilde{A}$.

\section{PROOF:}

$$
\begin{gathered}
\eta=\beta G(\tilde{A})=\left(1-\frac{f_{F}}{\gamma S}\right) G(\tilde{A}) . \\
\frac{\partial \eta}{\partial \tilde{A}}=\beta g(\tilde{A})+G(\tilde{A}) \frac{f_{F}}{\gamma S^{2}} \frac{\partial S}{\partial \tilde{A}}>0 .
\end{gathered}
$$

For Case 3, the overall welfare effect can be written as:

$$
\begin{gathered}
\frac{d S W L\left(\lambda_{D}\right)}{d \tilde{A}}=\left(l_{W}-l_{D}\right) \frac{\left(\tilde{A}+C_{D}\right) g(\tilde{A})}{\frac{\partial K\left(\lambda_{D}\right)}{\partial \lambda_{D}}}- \\
-\lambda_{D} \frac{\left(\tilde{A}+C_{D}\right) g(\tilde{A})}{S} f_{F}+\lambda_{D}\left(C_{P}+C_{D}\right) \frac{\partial \rho}{\partial \tilde{A}}+\lambda_{D} \theta\left(\frac{\partial \eta}{\partial \tilde{A}}\right) .
\end{gathered}
$$


It is easy to show that the welfare analysis and main qualitative findings obtained in Case 1 also hold in Case 3. In particular, if the defendants are underdeterred and the positive effect on the expansion of access to justice is high enough, a cost-reducing policy will be welfare improving. The positive effect of alleviating the lawyer's financial constraint on social welfare operates through the increase on access to justice by low-damage plaintiffs: More low-damage cases can now proceed to trial (i.e., there is a reduction on the zero offer associated with the dropping of low-damage cases). 


\section{APPENDIX B: COST-SHIFTING MODEL}

This appendix presents formal analysis of the cost-shifting model.

\subsection{MAIN MATERIAL}

This section includes the technical conditions, the proofs of Lemmas 6-7, and the proofs of Propositions $4-5$.

\subsubsection{TECHNICAL CONDITIONS}

Consider the following three technical conditions. ${ }^{5}$

$$
\begin{gathered}
f_{F}<\tilde{A}^{\prime \prime}-C_{P}^{1} . \\
\mu>\frac{\int_{\tilde{A}^{\prime \prime}}^{\bar{A}}\left(A+C_{D}\right) g(A) d A}{\left(\tilde{A}^{\prime \prime}-C_{P}^{1}\right)}-1 .
\end{gathered}
$$

There exits $\kappa>0$, such that for any $A \in\left(\tilde{A}^{\prime \prime}, \bar{A}\right)$

$$
g(A)-\max \left(C_{D}+C_{P}^{1}, A-C_{P}^{1}\right) g^{\prime}(A)>\kappa
$$

\subsubsection{LEMMAS AND PROOF}

LEMMA 6. The system (B4)-(B5)

$$
\begin{gathered}
\nu^{\prime \prime} S^{\prime \prime}+\int_{\tilde{A}^{\prime \prime}}^{S^{\prime \prime}+C_{P}^{1}} S^{\prime \prime} g(A) d A+\int_{S^{\prime \prime}+C_{P}^{1}}^{\bar{A}}\left(A+C_{D}\right) g(A) d A=\int_{\tilde{A}^{\prime \prime}}^{\bar{A}}\left(A+C_{D}\right) g(A) d A \\
\nu^{\prime \prime}+G\left(S^{\prime \prime}+C_{P}^{1}\right)-G\left(\tilde{A}^{\prime \prime}\right)=\left(C_{D}+C_{P}^{1}\right) g\left(S^{\prime \prime}+C_{P}^{1}\right)
\end{gathered}
$$

\footnotetext{
${ }^{5}$ These conditions are modified versions of conditions (2), (3) and (4).
}

${ }^{6}$ These equations are modified versions of equations (5) and (6) for the cost-shift model. 
has a unique solution $\left(S^{\prime \prime}, \nu^{\prime \prime}\right)$ for a sufficiently large value of $\bar{A}$.

\section{PROOF:}

Inserting equation (B5) into (B4) yields (after some algebra):

$$
\int_{\tilde{A}^{\prime \prime}}^{S^{\prime \prime}+C_{P}^{1}}\left(A+C_{D}-S^{\prime \prime}\right) g(A) d A-S^{\prime \prime}\left[\left(C_{D}+C_{P}^{1}\right) g\left(S^{\prime \prime}+C_{P}^{1}\right)-G\left(S^{\prime \prime}+C_{P}^{1}\right)+G\left(\tilde{A}^{\prime \prime}\right)\right]=0 .
$$

Denote the left-hand side of the last equation as $\Psi\left(S^{\prime \prime}\right)$, a function of $S^{\prime \prime}$. We will show that:

(1) The function $\Psi\left(S^{\prime \prime}\right)$ is continuous on $\left[\tilde{A}^{\prime \prime}-C_{P}^{1}, \bar{A}\right] ;(2) \frac{\partial \Psi}{\partial S^{\prime \prime}}>0 ;(3) \Psi\left(\tilde{A}^{\prime \prime}-C_{P}^{1}\right)<0$; (4) $\Psi(\bar{A})>0$ for sufficiently large value of $\bar{A} ;(5)$ equation $\Psi\left(S^{\prime \prime}\right)=0$ has exactly one solution.

(1) Continuity of $\Psi\left(S^{\prime \prime}\right)$ immediately follows from the assumptions about the functions $G(A)$ and $g(A)$.

(2) $\frac{\partial \Psi}{\partial S^{\prime \prime}}>0$.

Straightforward differentiation (and further algebraic transformations) yields:

$$
\frac{\partial \Psi}{\partial S^{\prime \prime}}=S^{\prime \prime}\left[g\left(S^{\prime \prime}+C_{P}^{1}\right)-\left(S^{\prime \prime}+C_{P}^{1}\right) g^{\prime}\left(S^{\prime \prime}+C_{P}^{1}\right)\right]>0 .
$$

The last inequality holds by technical condition (B3).

(3) $\Psi\left(\tilde{A}^{\prime \prime}-C_{P}^{1}\right)<0$.

$$
\Psi\left(\tilde{A}^{\prime \prime}-C_{P}^{1}\right)=-S^{\prime \prime}\left(C_{D}+C_{P}^{1}\right) g\left(\tilde{A}^{\prime \prime}\right)<0
$$

(4) $\Psi(\bar{A})>0$ for sufficiently large value of $\bar{A}$.

By condition (B3) and the result obtained in Step 2,

$$
\begin{gathered}
\Psi\left(S^{\prime \prime}\right)=\Psi\left(\tilde{A}^{\prime \prime}-C_{P}^{1}\right)+\int_{\left(\tilde{A}^{\prime \prime}-C_{P}^{1}\right)}^{S^{\prime \prime}} \frac{\partial \Psi}{\partial t} d t \geq \Psi\left(\tilde{A}^{\prime \prime}-C_{P}^{1}\right)+ \\
+\int_{\left(\tilde{A}^{\prime \prime}-C_{P}^{1}\right)}^{S^{\prime \prime}} S^{\prime \prime} \kappa d t \geq \Psi\left(\tilde{A}^{\prime \prime}-C_{P}^{1}\right)+S^{\prime \prime} \kappa\left(S^{\prime \prime}-\tilde{A}^{\prime \prime}+C_{P}^{1}\right)= \\
=\Psi\left(\tilde{A}^{\prime \prime}-C_{P}^{1}\right)+\kappa S^{\prime \prime}\left(S^{\prime \prime}-\tilde{A}^{\prime \prime}+C_{P}^{1}\right) .
\end{gathered}
$$


The last expression is positive for

$$
S^{\prime \prime}>\frac{\left(\tilde{A}^{\prime \prime}-C_{P}^{1}\right) \kappa+\sqrt{\left(\tilde{A}^{\prime \prime}-C_{P}^{1}\right)^{2} \kappa^{2}-4 \kappa \psi\left(\tilde{A}^{\prime \prime}-C_{P}^{1}\right)}}{2 \kappa} .
$$

This is why for

$$
\begin{gathered}
\bar{A}>\frac{\left(\tilde{A}^{\prime \prime}-C_{P}^{1}\right) \kappa+\sqrt{\left(\tilde{A}^{\prime \prime}-C_{P}^{1}\right)^{2} \kappa^{2}-4 \kappa \psi\left(\tilde{A}^{\prime \prime}-C_{P}^{1}\right)}}{2 \kappa}, \\
\Psi(\bar{A})>0
\end{gathered}
$$

(5) In the previous stages, we showed that $\Psi\left(S^{\prime \prime}\right)$ is a continuous and monotonic function with $\Psi\left(\tilde{A}^{\prime \prime}-C_{P}^{1}\right)<0$ and $\Psi(\bar{A})>0$. Hence, there exists a unique $S^{\prime \prime} \in\left(\tilde{A}^{\prime \prime}-C_{P}^{1}, \bar{A}\right)$ such that $\Psi\left(S^{\prime \prime}\right)=0$.

By equation (B5), existence and uniqueness of $S^{\prime \prime}$ implies existence and uniqueness of $\nu^{\prime \prime}$.

LEMMA 7. The difference between the total mass of low-damage cases and the mass of lowand no-damage cases that are filed, $\left[G\left(\tilde{A}^{\prime \prime}\right)-\nu^{\prime \prime}\right]$, is increasing in $\tilde{A}^{\prime \prime}$.

\section{PROOF:}

Taking into account equation (B5), total differentiation of equation (B4) yields after some algebraic transformation:

$$
\frac{\partial \nu^{\prime \prime}}{\partial \tilde{A}^{\prime \prime}}=\frac{\left(S^{\prime \prime}-\tilde{A}^{\prime \prime}-C_{D}\right) g\left(\tilde{A^{\prime \prime}}\right)}{S^{\prime \prime}}
$$

Hence,

$$
\frac{\partial\left[G\left(\tilde{A^{\prime \prime}}\right)-\nu^{\prime \prime}\right]}{\partial \tilde{A}^{\prime \prime}}=g\left(\tilde{A^{\prime \prime}}\right)-\frac{\partial \nu^{\prime \prime}}{\partial \tilde{A}^{\prime \prime}}=\frac{\left(\tilde{A}^{\prime \prime}+C_{D}\right) g\left(\tilde{A}^{\prime \prime}\right)}{S^{\prime \prime}}>0
$$




\subsubsection{PROPOSITIONS AND PROOFS}

PROPOSITION 4. Assume that conditions (B3)-(B5) hold. Then, the following strategy profile, together with the defendant's beliefs, represents the perfect Bayesian equilibrium of the game.

Case 1: $G\left(\tilde{A}^{\prime \prime}\right)-\nu^{\prime \prime}>0$

(1) The defendant chooses probability of accident (level of care) $\lambda_{D}^{\prime \prime}=\arg \min \{K(\lambda)+$ $\left.\lambda \int_{\tilde{A}^{\prime \prime}}^{\bar{A}}\left(A+C_{D}\right) g(A) d A\right\}$. If the plaintiff files a lawsuit, the defendant mixes between proposing a zero offer with probability $\beta^{\prime \prime}=1-\frac{f_{M}}{\gamma S^{\prime \prime}+(1-\gamma) f_{M}}$ and proposing an offer $S^{\prime \prime}>0$ with the complementary probability.

(2) A high-damage case is always filed by the plaintiff's attorney; a low-damage case is filed with probability $\frac{\nu^{\prime \prime}}{G\left(\tilde{A}^{\prime \prime}\right)}$; a no-damage case is never filed.

(3) A high-damage plaintiff always rejects a zero offer and accepts an offer $S^{\prime \prime}>0$ only if $A-C_{P}^{1} \leq S^{\prime \prime}$; a low-damage plaintiff always accepts a non-negative offer; a no-damage plaintiff always accepts a non-negative offer.

(4) The defendant's equilibrium beliefs are as follows. When the defendant observes a lawsuit, he believes that $P(A=0)=0, P\left(0<A<\tilde{A}^{\prime \prime}\right)=\frac{\nu^{\prime \prime}}{\nu^{\prime \prime}+1-G\left(\tilde{A}^{\prime \prime}\right)}, P\left(\tilde{A}^{\prime \prime} \leq A \leq y\right)=\frac{G(y)-G\left(\tilde{A}^{\prime \prime}\right)}{\nu^{\prime \prime}+1-G\left(\tilde{A}^{\prime \prime}\right)}$ for any $y \in\left[\tilde{A}^{\prime \prime}, \bar{A}\right]$.

Case 2: $G\left(\tilde{A^{\prime \prime}}\right)-\nu^{\prime \prime}=0$

(1) The defendant chooses probability of accident (level of care) $\lambda_{D}^{\prime \prime}=\arg \min \{K(\lambda)+$ $\left.\lambda \int_{\tilde{A}^{\prime \prime}}^{\bar{A}}\left(A+C_{D}\right) g(A) d A\right\}$. If the plaintiff files a lawsuit, the defendant mixes between proposing a zero offer with probability $\beta^{\prime \prime} \in\left(1-\frac{f_{F}}{\gamma S^{\prime \prime}+(1-\gamma) f_{F}}, 1-\frac{f_{M}}{\gamma S^{\prime \prime}+(1-\gamma) f_{M}}\right)$ and proposing an offer $S^{\prime \prime}>0$ with the complementary probability.

(2) A high-damage case is always filed by the plaintiff's attorney; a low-damage case is always filed; a no-damage case is never filed.

(3) A high-damage plaintiff always rejects a zero offer and accepts an offer $S^{\prime \prime}$ only if $A-C_{P}^{1} \leq$ $S^{\prime \prime}$; a low-damage plaintiff always accepts a non-negative offer; a no-damage plaintiff always accepts a non-negative offer. 
(4) The defendant's equilibrium beliefs are as follows. When the defendant observes a lawsuit, he believes that $P(A=0)=0, P(0<A \leq y)=G(y)$ for any $y \in(0, \bar{A}]$.

Case 3: $G\left(\tilde{A}^{\prime \prime}\right)-\nu^{\prime \prime}<0$

(1) The defendant chooses probability of accident (level of care) $\lambda_{D}^{\prime \prime}=\arg \min \{K(\lambda)+$ $\left.\lambda \int_{\tilde{A}^{\prime \prime}}^{\bar{A}}\left(A+C_{D}\right) g(A) d A\right\}$. If the plaintiff files a lawsuit, the defendant mixes between proposing a zero offer with probability $\beta^{\prime \prime}=1-\frac{f_{F}}{\gamma S^{\prime \prime}+(1-\gamma) f_{F}}$ and proposing an offer $S^{\prime \prime}>0$ with the complementary probability.

(2) A high-damage case is always filed by the plaintiff's attorney; a low-damage case is always filed; a no-damage case is filed with probability $\frac{\nu^{\prime \prime}-G\left(\tilde{A}^{\prime \prime}\right)}{\mu}$.

(3) A high-damage plaintiff always rejects a zero offer and accepts an offer $S^{\prime \prime}$ only if $A-C_{P}^{1} \leq$ $S^{\prime \prime}$; a low-damage plaintiff always accepts a non-negative offer; a no-damage plaintiff always accepts a non-negative offer.

(4) The defendant's equilibrium beliefs. When the defendant observes a lawsuit, he believes that $P(A=0)=\frac{\nu^{\prime \prime}-G\left(\tilde{A}^{\prime \prime}\right)}{\nu^{\prime \prime}+1-G\left(\tilde{A}^{\prime \prime}\right)}, P(0<A \leq y)=\frac{G(y)}{\nu^{\prime \prime}+1-G\left(\tilde{A}^{\prime \prime}\right)}$ for any $y \in(0, \bar{A}]$.

PROOF: The proof consists of several steps.

Step 1. It is simple to show that offers lower than zero and greater than $\bar{A}$ are strictly dominated strategies. Offers $S^{\prime \prime} \in(0, \tilde{A})$ are not in the set of equilibrium offers. Offers $S^{\prime \prime}$ $\in\left(0, \tilde{A}^{\prime \prime}-C_{P}^{1}\right)$ are not in the set of equilibrium offers. Any offer in this range will be accepted by no-damage plaintiffs (losses equal to zero) and low-damage plaintiffs $\left(0<A<\tilde{A}^{\prime \prime}-C_{P}^{1}\right)$ and rejected by high-damage plaintiffs $\left(A \geq \tilde{A}^{\prime \prime}-C_{P}^{1}\right)$. Then, the defendant is better off by making a zero offer instead of making an offer $S^{\prime \prime} \in\left(0, \tilde{A}^{\prime \prime}-C_{P}^{1}\right)$.

Step 2. A zero offer must be in the set of equilibrium offers, otherwise all non-meritorious cases $(A=0)$ are filed. Suppose not. Then the defendant always offers at least $\tilde{A}^{\prime \prime}-C_{P}^{1}$. Under condition (B1), all non-meritorious cases are filed. The defendant will lose no less than $(1+\mu)\left(\tilde{A}^{\prime \prime}-C_{P}^{1}\right)$, where $\mu$ is the measure of non-meritorious potential plaintiffs. Assuming $\mu$ is large enough (ensured by condition (B2)), this loss (which is at least as large as $(1+\mu)\left(\tilde{A}^{\prime \prime}-C_{P}^{1}\right)$ will be greater than the loss from offering $0, \int_{\tilde{A}^{\prime \prime}}^{\bar{A}}\left(A+C_{D}\right) g(A) d A$. 
Step 3. A zero offer cannot be the only offer. Suppose not, the defendant always offers 0 . Then, only cases with types

$$
A \geq \hat{A}^{\prime \prime} \equiv f_{M}+C_{P}^{1}+\frac{C_{P}^{2}+\left(C_{P}+f_{M}-x\right) r}{\gamma}
$$

will be filed. Attorneys with non-meritorious plaintiffs $(A=0)$ and attorneys with plaintiffs of type $A \in\left(0, \hat{A}^{\prime \prime}\right)$ cannot file, as they expect a negative expected payoff. But then a zero offer is not the optimal offer. This is because the defendant can offer $\hat{A}^{\prime \prime}-C_{P}^{1}+\epsilon$ and save litigation costs $C_{D}$ when facing a plaintiff of a type $\hat{A}^{\prime \prime} \leq A \leq \hat{A}^{\prime \prime}+\epsilon$. If $\epsilon<C_{D}$, the defendant's expected litigation loss will be $\int_{\hat{A}^{\prime \prime}}^{\hat{A}^{\prime \prime}+\epsilon}\left(\hat{A}^{\prime \prime}-C_{P}^{1}+\epsilon\right) g(A) d A<\int_{\hat{A}^{\prime \prime}}^{\hat{A}^{\prime \prime}+\epsilon}\left(A+C_{D}\right) g(A) d A$. Hence, there is at least one positive offer $S$.

Step 4. There must be no-damage $(A=0)$ or low-damage cases $\left(0<A<\tilde{A}^{\prime \prime}\right)$ that are filed. The logic follows the logic of Step 4 in the proof of Proposition 1. Hence, $\nu^{\prime \prime}>0$.

Step 5. Low-damage plaintiffs $\left(0<A<\tilde{A}^{\prime \prime}\right)$ should get a positive expected settlement offer $E\left(S^{\prime \prime}\right)$ that makes their attorneys at least indifferent between filing and not filing. The plaintiff with $A<\tilde{A}^{\prime \prime}$ always accepts the out-of-court settlement offer. If this is a zero offer, then the plaintiff drops the case. Otherwise, the plaintiff gets a positive out-of-court settlement compensation. The positive probability of getting a positive expected offer $E\left(S^{\prime \prime}\right)$, defined as $\left(1-b^{\prime \prime}\right)$ (the probability of getting a zero offer is defined as $\left.b^{\prime \prime}\right)$, ensures a non-negative payoff net of filing cost for the attorney. Mathematically,

$$
\gamma\left[b^{\prime \prime} \bullet 0+\left(1-b^{\prime \prime}\right) E\left(S^{\prime \prime}\right)\right]-f_{M} \geq 0
$$

Step 6. All high-damage cases $\left(A \geq \tilde{A}^{\prime \prime}\right)$ are filed.

For a high-damage case, the attorney's expected payoff at the filing stage is

$$
\left(1-b^{\prime \prime}\right) \gamma E\left(S^{\prime \prime}\right)+b^{\prime \prime}\left[\gamma\left(A-C_{P}^{1}\right)-C_{P}^{2}+(1-\gamma) f_{M}-\left(C_{P}+f_{M}-x\right) r\right]-f_{M}
$$

The last expression is non-negative for $A=\tilde{A}^{\prime \prime}$ and strictly positive for $A>\tilde{A}^{\prime \prime}$.

Step 7. We established that there are at least two offers, 0 and some $S^{\prime \prime} \geq \tilde{A}^{\prime \prime}$. This implies that the positive offer $S^{\prime \prime}$ must minimize the expected loss of the defendant, and the defendant must 
be indifferent between offering 0 and $S^{\prime \prime}$. We write down the indifference condition (equation (B4))

$$
\nu^{\prime \prime} S^{\prime \prime}+\int_{\tilde{A}^{\prime \prime}}^{S^{\prime \prime}+C_{P}^{1}} S^{\prime \prime} g(A) d A+\int_{S^{\prime \prime}+C_{P}^{1}}^{\bar{A}}\left(A+C_{D}\right) g(A) d A=\int_{\tilde{A}^{\prime \prime}}^{\bar{A}}\left(A+C_{D}\right) g(A) d A
$$

The first-order optimality condition below indicates that the defendant minimizes the expected litigation loss with respect to $S^{\prime \prime}$ over the interval $\left[\tilde{A}^{\prime \prime}, \bar{A}\right]$, i.e., he takes into account that all plaintiffs with $A \geq \tilde{A}^{\prime \prime}$ file (Step 6) and that $\nu^{\prime \prime}>0$ (Step 4).

$$
\frac{\partial}{\partial S^{\prime \prime}}\left[\nu^{\prime \prime} S^{\prime \prime}+\int_{\tilde{A}^{\prime \prime}}^{S^{\prime \prime}+C_{P}^{1}} S g(A) d A+\int_{S^{\prime \prime}+C_{P}^{1}}^{\bar{A}}\left(A+C_{D}\right) g(A) d A\right]=0 .
$$

This last equation simplifies to equation (B5) when evaluated at $S=S^{\prime \prime}$.

$$
\nu^{\prime \prime}+G\left(S^{\prime \prime}+C_{P}^{1}\right)-G\left(\tilde{A}^{\prime \prime}\right)=\left(C_{D}+C_{P}^{1}\right) g\left(S^{\prime \prime}+C_{P}^{1}\right)
$$

Assuming that $\bar{A}$ is large enough (so that $\bar{A}>S^{\prime \prime}$ ) and that the second-order optimality condition

$$
g(A)>\left(C_{D}+C_{P}^{1}\right) \frac{\partial g(A)}{\partial A}
$$

is satisfied for all $A \in\left[\tilde{A}^{\prime \prime}, \bar{A}\right]$ (ensured by condition (B3)), we establish in Lemma 1 that there is a unique positive offer, and a unique equilibrium mass of no-damage and low-damage cases that are filed.

Step 8. The prevalent magnitude of the lawyers' financial constraints $\tilde{A}^{\prime \prime}$ (the state of the world) determines one of three mutually-exclusive scenarios: $G\left(\tilde{A^{\prime \prime}}\right)-\nu^{\prime \prime}>0, G\left(\tilde{A^{\prime \prime}}\right)-\nu^{\prime \prime}=0$, and $G\left(\tilde{A^{\prime \prime}}\right)-\nu^{\prime \prime}<0$. We call these three scenarios, Case 1, Case 2, and Case 3, respectively. Lemma 7 shows that a relaxation of the lawyers' financial constraints (i.e., a reduction in $\tilde{A}^{\prime \prime}$ ) lowers $G\left(\tilde{A}^{\prime \prime}\right)-\nu^{\prime \prime}$. If there exists $\tilde{A}^{\prime \prime *}$ such that $G\left(\tilde{A}^{\prime \prime *}\right)=\nu\left(\tilde{A}^{\prime \prime *}\right)($ Case 2$)$, then for $\tilde{A}^{\prime \prime}>\tilde{A}^{\prime \prime *}$, $G(\tilde{A})>\nu$ (Case 1) and for $\tilde{A}^{\prime \prime}<\tilde{A}^{\prime \prime *}, G\left(\tilde{A}^{\prime \prime}\right)<\nu^{\prime \prime}$ (Case 3).

Step 9. Cases 1, 2, and 3 involve different compositions of equilibrium $\nu^{\prime \prime}$, and hence, different compositions of the equilibrium mass of filed cases $\zeta^{\prime \prime}$. Next, we analyze the composition of equilibrium $\nu^{\prime \prime}$ and $\beta^{\prime \prime}$ for Cases 1,2 , and 3. 
(1) Case 1: The equilibrium mass of low- and no-damage cases that are filed $\nu^{\prime \prime}$ is lower than the total mass of low-damage cases $G\left(\tilde{A}^{\prime \prime}\right)$, then the equilibrium mass of filed cases includes all high-damage cases and a subset of low-damage cases.

An attorney with a high-damage client is always willing to file a lawsuit (by Step 6).

An attorney with an average low-damage client mixes between filing and not filing. ${ }^{7}$ Hence, he must be indifferent between these two strategies. The indifference condition

$$
f_{M}=\beta^{\prime \prime} \bullet 0+\left(1-\beta^{\prime \prime}\right)\left[S^{\prime \prime}-(1-\gamma)\left(S^{\prime \prime}-f_{M}\right)\right]
$$

yields $\beta^{\prime \prime}$, the probability that the defendant makes a zero offer.

$$
\beta^{\prime \prime}=1-\frac{f_{M}}{\gamma S^{\prime \prime}+(1-\gamma) f_{M}} .
$$

Like in the benchmark model, an attorney with a no-damage client never files a lawsuit because his expected payoff is negative, $-f_{F}+f_{M}<0$.

The mass of low-damage cases that are filed is $\nu^{\prime \prime}$ and the total mass of low-damage cases is $G\left(\tilde{A}^{\prime \prime}\right)$. Hence, the probability of filing for an average low-damage case is $\frac{\nu^{\prime \prime}}{G\left(\tilde{A}^{\prime \prime}\right)}$.

(2) Case 2: The equilibrium mass of low- and no-damage cases that are filed $\nu^{\prime \prime}$ is equal to the total mass of low-damage cases $G\left(\tilde{A}^{\prime \prime}\right)$, then the equilibrium mass of filed cases includes all high-damage and all low-damage cases.

An attorney with a high-damage case is always willing to file a lawsuit (by Step 6).

An attorney with a low-damage client is always willing to file a lawsuit but an attorney with a no-damage client will never file a lawsuit. Mathematically,

$$
\beta^{\prime \prime} \bullet 0+\left(1-\beta^{\prime \prime}\right)\left[S^{\prime \prime}-(1-\gamma)\left(S^{\prime \prime}-f_{M}\right)\right]>f_{M}
$$

but

$$
\beta^{\prime \prime} \bullet 0+\left(1-\beta^{\prime \prime}\right)\left[S^{\prime \prime}-(1-\gamma)\left(S^{\prime \prime}-f_{F}\right)\right]<f_{F},
$$

\footnotetext{
${ }^{7}$ In principle, the probability of filing for a low-damage plaintiff may depend on the specific $A$. That's the reason behind the expression "average low-damage client."
} 
which yields the range of values $\beta^{\prime \prime} \in\left(1-\frac{f_{M}}{\gamma S^{\prime \prime}+(1-\gamma) f_{M}}, 1-\frac{f_{F}}{\gamma S^{\prime \prime}+(1-\gamma) f_{F}}\right)$.

(3) Case 3: The equilibrium mass of low- and no-damage cases that are filed $\nu^{\prime \prime}$ is greater than the total mass of low-damage cases $G\left(\tilde{A}^{\prime \prime}\right)$, then the equilibrium mass of filed cases includes all high-damage, all low-damage, and a subset of no-damage cases.

An attorney with a high-damage client is always willing to file a lawsuit (by Step 6).

An attorney with a no-damage client must be indifferent between filing and not filing. The indifference condition

$$
f_{F}=\beta^{\prime \prime} \bullet 0+\left(1-\beta^{\prime \prime}\right)\left[\gamma S^{\prime \prime}+(1-\gamma) f_{F}\right]
$$

yields $\beta^{\prime \prime}$, the probability that the defendant makes a zero offer.

$$
\beta^{\prime \prime}=1-\frac{f_{F}}{\gamma S^{\prime \prime}+(1-\gamma) f_{F}}
$$

Like in the benchmark model, an attorney with a low-damage client always files a lawsuit because his expected payoff is $f_{F}-f_{M}>0$.

The mass of no-damage cases that are filed is $\nu^{\prime \prime}-G\left(\tilde{A}^{\prime \prime}\right)$ and the total mass of no-damage cases is $\mu$. Hence, the probability of filing for a no-damage case is $\frac{\nu^{\prime \prime}-G\left(\tilde{A}^{\prime \prime}\right)}{\mu}$.

Step 10. The equilibrium strategies of the average plaintiff and his attorney and the equilibrium mass of filed cases determine the beliefs of the defendant.

Case 1: All high-damage cases and a subset of low-damage cases are filed, but no-damage cases are not filed. The mass of high-damage cases that are filed is equal to the total mass of high-damage cases, $1-G\left(\tilde{A}^{\prime \prime}\right)$. $\nu^{\prime \prime}$ includes only the subset of low-damage cases that are filed. Therefore, the total mass of filed cases is $1-G\left(\tilde{A}^{\prime \prime}\right)+\nu^{\prime \prime}$. As no-damage cases are not filed, the posterior (conditional on filing) probability of a no-damage case is 0 , the posterior probability of an average low-damage case is $\frac{\nu^{\prime \prime}}{G\left(\tilde{A}^{\prime \prime}\right)}$, while the posterior probability of an average highdamage case is $\frac{1-G\left(\tilde{A}^{\prime \prime}\right)}{1-G\left(\tilde{A}^{\prime \prime}\right)+\nu^{\prime \prime}}$. Given that all high-damage cases are filed and the distribution $G(A)$ is known by the defendant, he computes the posterior probability for any range of highdamage cases as the product of conditional probability for this particular range (conditional 
on a case being a high-damage case) and the posterior probability of a high-damage case. Mathematically, for any $y \in\left(\tilde{A}^{\prime \prime}, \bar{A}\right]$,

$$
P\left(\tilde{A}^{\prime \prime}<A \leq y \mid \text { Filing }\right)=\frac{G(y)-G\left(\tilde{A}^{\prime \prime}\right)}{1-G\left(\tilde{A}^{\prime \prime}\right)} \frac{1-G\left(\tilde{A}^{\prime \prime}\right)}{1-G\left(\tilde{A}^{\prime \prime}\right)+\nu^{\prime \prime}}=\frac{G(y)-G\left(\tilde{A}^{\prime \prime}\right)}{1-G\left(\tilde{A}^{\prime \prime}\right)+\nu^{\prime \prime}} .
$$

Case 2: All high- and low-damage cases are filed but no-damage cases are not filed. The mass of filed cases (low-damage cases and high-damage cases) equals 1. Therefore, the posterior (conditional on filing) distribution of damage levels is described by the $\operatorname{cdf} G(A)$. Mathematically, for any $y \in(0, \bar{A}]$,

$$
P(0<A \leq y \mid \text { Filing })=G(y)
$$

Case 3: All high- and low-damage cases are filed, and $\nu^{\prime \prime}-G\left(\tilde{A}^{\prime \prime}\right)$ of no-damage cases are filed. This is why the total mass of filed cases is $1-G\left(\tilde{A}^{\prime \prime}\right)+\nu^{\prime \prime}$. Therefore, the posterior probability of a no-damage case is $\frac{\nu^{\prime \prime}-G\left(\tilde{A}^{\prime \prime}\right)}{1-G\left(\tilde{A}^{\prime \prime}\right)+\nu^{\prime \prime}}$, and the posterior probability of a meritorious case (highdamage, or low-damage case) is $\frac{1}{1-G\left(\tilde{A}^{\prime \prime}\right)+\nu^{\prime \prime}}$. Given that all meritorious cases are filed and the distribution $G(A)$ is known by the defendant, he computes the posterior probability for any range of meritorious cases as the product of conditional probability for this particular range (conditional on a case being a meritorious case) and the posterior probability of a meritorious case. Mathematically, for any $y \in(0, \bar{A}]$,

$$
P(\tilde{0}<A \leq y \mid \text { Filing })=G(y) \frac{1}{1-G\left(\tilde{A}^{\prime \prime}\right)+\nu^{\prime \prime}}=\frac{G(y)}{1-G\left(\tilde{A}^{\prime \prime}\right)+\nu^{\prime \prime}} .
$$

Step 11. Analyze the defendant's optimal level of care. The defendant's optimal probability for an accident is given by $\lambda_{D}^{\prime \prime}={ }_{D}=\arg \min \left\{K^{\prime \prime}(\lambda)+\lambda l_{D}^{\prime \prime}\right\}=\arg \min \left\{K^{\prime \prime}(\lambda)+\lambda \int_{\tilde{A}^{\prime \prime}}^{\bar{A}}(A+\right.$ $\left.\left.C_{D}\right) g(A) d A\right\}$. By Lemma 3 (Appendix A), for any positive value of $l_{D}^{\prime \prime}$, the function $K^{\prime \prime}(\lambda)+\lambda l_{D}^{\prime \prime}$ has a unique interior minimum $\lambda_{D}^{\prime \prime} \in(0,1)$.

PROPOSITION 5. A cost-shifting policy: (1) increases the expected litigation loss of the defendant; (2) reduces the probability of an accident; (3) reduces the (strictly) positive out-ofcourt settlement offer; (4) increases the mass of filed cases; (5) might increase or reduce the probability of a zero offer; and (6) increases the probability of trial if $C_{D}<\tilde{A}^{\prime \prime}$. 


\section{PROOF:}

(1) The expected litigation loss of the defendant is:

$$
\begin{gathered}
l_{D}^{\prime \prime}=\int_{\tilde{A}^{\prime \prime}}^{\bar{A}}\left(A+C_{D}\right) g(A) d A \\
\frac{\partial l_{D}}{\partial \tilde{A}^{\prime \prime}}=-\left(\tilde{A}^{\prime \prime}+C_{D}\right) g\left(\tilde{A}^{\prime \prime}\right)<0 .
\end{gathered}
$$

As $\tilde{A}^{\prime \prime}<\tilde{A}$

$$
l_{D}^{\prime \prime}>l_{D}=\int_{\tilde{A}}^{\bar{A}}\left(A+C_{D}\right) g(A) d A .
$$

This result applies to Cases 1 and 3 and across cases.

(2) By Lemma 3, an increase in the defendant's expected litigation loss increases the spending on care and, therefore, reduces the probability of an accident. This result applies to Cases 1 and 3 and across cases.

(3)-(4) Consider Case 1. We will show that a cost-shifting policy reduces the positive offer to settle, $S$, and raises the overall measure of filing, $1-G(\tilde{A})+\nu$. Specifically, we will assess the effects of a cost-shift policy by considering the effects of a reduction in $\tilde{A}$ (when $C_{P}^{1}=0$; i.e., in the benchmark model) and an increase in $C_{P}^{1}$ (for a given $\tilde{A}^{\prime \prime}$ ). From the analysis of the benchmark model (where $C_{P}^{1}=0$ ), we know that a reduction in $\tilde{A}$ lowers the likelihood of a positive offer $S$ and increases filing. We will show now that an increase in $C_{P}^{1}$ (for a given $\tilde{A}^{\prime \prime}$ ) affects the likelihood of a positive offer $S^{\prime \prime}$ and filing in similar ways: $\frac{\partial S^{\prime \prime}}{\partial C_{P}^{1}}<0$ and $\frac{\partial \nu^{\prime \prime}}{\partial C_{P}^{1}}>0$.

Total differentiation of equations (B4) and (B5) yield (after some algebra):

$$
\begin{gathered}
\frac{\partial S^{\prime \prime}}{\partial C_{P}^{1}}=-\frac{\left(C_{P}^{1}+C_{D}\right)\left[g\left(S^{\prime \prime}+C_{P}^{1}\right)-S^{\prime \prime} g^{\prime}\left(S^{\prime \prime}+C_{P}^{1}\right)\right]}{S^{\prime \prime}\left[g\left(S^{\prime \prime}+C_{P}^{1}\right)-\left(C_{D}+C_{P}^{1}\right) g^{\prime}\left(S^{\prime \prime}+C_{P}^{1}\right)\right]}<0 . \\
\frac{\partial \nu^{\prime \prime}}{\partial C_{P}^{1}}=\frac{\left(C_{D}+C_{P}^{1}\right) g\left(S^{\prime \prime}+C_{P}^{1}\right)}{S\left[g\left(S^{\prime \prime}+C_{P}^{1}\right)-\left(C_{D}+C_{P}^{1}\right) g^{\prime}\left(S^{\prime \prime}+C_{P}^{1}\right)\right]}>0 .
\end{gathered}
$$

By condition (4), both inequalities are satisfied. This result also applies to Case 3 and across cases. 
(5) Consider Case 1. The change in the probability of the zero offer is:

$$
\beta^{\prime \prime}-\beta=\left(1-\frac{f_{M}}{\gamma S^{\prime \prime}+(1-\gamma) f_{M}}\right)-\left(1-\frac{f_{M}}{\gamma S}\right)=\frac{f_{M}\left[\gamma\left(S^{\prime \prime}-S\right)+(1-\gamma) f_{M}\right]}{\gamma S\left[\gamma S^{\prime \prime}+(1-\gamma) f_{M}\right]} .
$$

The last expression can be positive, or negative, because $S^{\prime \prime}<S$, but the term $(1-\gamma) f_{M}$ is positive. Similar analysis applies to Case 3.

(6) Consider Case 1. Define an auxiliary function

$$
\Omega(\tilde{A}, S(\tilde{A}))=\left(1-\frac{f_{M}}{\gamma S}\right)(1-G(\tilde{A}))+\frac{f_{M}}{\gamma S}(1-G(S)),
$$

where

$$
\frac{\partial S}{\partial \tilde{A}}>0
$$

We will show that

$$
\rho\left(\tilde{A}^{\prime \prime}, S^{\prime \prime}\right)>\Omega\left(\tilde{A}^{\prime \prime}, S^{\prime \prime}\right)>\rho(\tilde{A}, S) .
$$

In part (6) of the proof of Proposition 2, we effectively showed that

$$
\frac{\partial \rho}{\partial \tilde{A}}<0
$$

i.e., where $\rho=\Omega$. Then, a reduction in $\tilde{A}$ increases the value of $\Omega$. Hence,

$$
\Omega\left(\tilde{A}^{\prime \prime}, S^{\prime \prime}\right)>\left(1-\frac{f_{M}}{\gamma S}\right)(1-G(\tilde{A}))+\frac{f_{M}}{\gamma S}(1-G(S))=\rho(\tilde{A}, S)
$$

Define a second auxiliary function

$$
Z(\pi)=\left(1-\frac{f_{M}}{\gamma S^{\prime \prime}+\pi}\right)\left(1-G\left(\tilde{A}^{\prime \prime}\right)\right)+\frac{f_{M}}{\gamma S^{\prime \prime}+\pi}\left(1-G\left(S^{\prime \prime}\right)\right)
$$

It is straightforward to verify that $Z(0)=\Omega\left(\tilde{A}^{\prime \prime}, S^{\prime \prime}\right)$, that $Z\left((1-\gamma) f_{M}\right)=\rho\left(\tilde{A}^{\prime \prime}, S^{\prime \prime}\right)$ and that

$$
\frac{\partial Z}{\partial \pi}>0
$$

This is why $\rho\left(\tilde{A}^{\prime \prime}, S^{\prime \prime}\right)>\Omega\left(\tilde{A}^{\prime \prime}, S^{\prime \prime}\right)$. This result also applies to Case 3 . 


\subsection{ADDITIONAL MATERIAL}

This section includes the analysis of equilibrium outcomes and payoffs, and the analysis of the effects of a cost-shifting policy on plaintiff's and attorneys' payoffs.

\subsubsection{EQUILIBRIUM OUTCOMES AND PAYOFFS}

The equilibrium outcomes and payoffs for Cases 1, 2, and 3 are as follows. When the analysis applies only to one case, the specific case will be mentioned before presenting the outcome or payoff.

(1) Mass of filed cases (conditional on accident occurrence):

$$
\zeta=\int_{\tilde{A}^{\prime \prime}}^{\bar{A}} g(A) d A+\nu^{\prime \prime}
$$

(2) Probability of trial (conditional on accident occurrence and filing):

$$
\rho=\beta^{\prime \prime}\left(1-G\left(\tilde{A}^{\prime \prime}\right)\right)+\left(1-\beta^{\prime \prime}\right)\left(1-G\left(S^{\prime \prime}\right)\right) .
$$

(3) Defendant's expected litigation loss (conditional on accident occurrence and filing):

$$
l_{D}=\int_{\tilde{A}^{\prime \prime}}^{\bar{A}}\left(A+C_{D}\right) g(A) d A
$$

(4) Plaintiff's expected payoff (conditional on accident occurrence and filing).

(4.1) No-damage plaintiff $(A=0)$.

Case 3:

$$
\beta^{\prime \prime} \bullet 0+\left(1-\beta^{\prime \prime}\right)(1-\gamma)\left(S^{\prime \prime}-f_{M}\right)=\left(1-\beta_{3}^{\prime \prime}\right)(1-\gamma)\left(S^{\prime \prime}-f_{M}\right)
$$

(4.2.) Low-damage plaintiff $\left(0 \leq A<\tilde{A}^{\prime \prime}\right)$ : 


$$
\beta^{\prime \prime} \bullet 0+\left(1-\beta^{\prime \prime}\right)(1-\gamma)\left(S^{\prime \prime}-f_{M}\right)=\left(1-\beta^{\prime \prime}\right)(1-\gamma)\left(S^{\prime \prime}-f_{M}\right) .
$$

(4.3) High-damage plaintiff of type $A \in\left[\tilde{A}, S^{\prime \prime}\right)$ :

$$
\beta^{\prime \prime}\left[(1-\gamma)\left(A-f_{M}-C_{P}^{1}\right)\right]+\left(1-\beta^{\prime \prime}\right)(1-\gamma)\left(S^{\prime \prime}-f_{M}\right) .
$$

(4.4) High-damage plaintiff of type $A \in\left[S^{\prime \prime}, \bar{A}\right]$ :

$$
(1-\gamma)\left(A-f_{M}-C_{P}^{1}\right)
$$

(5) Attorney's expected payoff (conditional on accident occurrence and filing).

(5.1) Attorney with no-damage client $(A=0)$.

Case 3:

$$
\beta^{\prime \prime} \bullet 0+\left(1-\beta^{\prime \prime}\right)\left[S^{\prime \prime}-(1-\gamma)\left(S^{\prime \prime}-f_{F}\right)\right]-f_{F}=0 .
$$

(5.2) Attorney with low-damage client $(0<A<\tilde{A})$.

Case 1:

$$
\beta^{\prime \prime} \bullet 0+\left(1-\beta^{\prime \prime}\right)\left[S^{\prime \prime}-(1-\gamma)\left(S^{\prime \prime}-f_{M}\right)\right]-f_{M}=0 .
$$

Case 2:

$$
\beta^{\prime \prime} \bullet 0+\left(1-\beta^{\prime \prime}\right)\left[S^{\prime \prime}-(1-\gamma)\left(S^{\prime \prime}-f_{M}\right)\right]-f_{M}>0 .
$$

Case 3:

$$
\beta^{\prime \prime} \bullet 0+\left(1-\beta^{\prime \prime}\right)\left[S^{\prime \prime}-(1-\gamma)\left(S^{\prime \prime}-f_{M}\right)\right]-f_{M}>0 .
$$

(5.3) Attorney with high-damage client of type $A \in\left[\tilde{A}, S^{\prime \prime}\right)$ :

$$
\beta^{\prime \prime}\left[\gamma\left(A-f_{M}-C_{P}^{1}\right)-C_{P}^{2}-\left(f_{M}+C_{P}-x\right) r\right]+\left(1-\beta^{\prime \prime}\right)\left(S^{\prime \prime}-f_{M}\right) .
$$


Table B1: Effects of Cost-Shifting Policy on Plaintiff's and Attorney's Payoffs

\begin{tabular}{lllll}
\hline \hline \multicolumn{2}{c}{ Plaintiff's Type Position } & & \multicolumn{2}{c}{ Payoff Effect } \\
\cline { 1 - 2 } \cline { 5 - 5 } Benchmark & Cost-Shifting & & Plaintiff & Attorney \\
\hline $0<A<\tilde{A}$ & $0<A<\tilde{A}^{\prime \prime}$ & & - & 0 \\
$0<A<\tilde{A}$ & $A>\tilde{A}^{\prime \prime}$ & & $+/-/ 0$ & + \\
$A>S$ & $A>S^{\prime \prime}$ & & - & + \\
$0<A<S$ & $A>S^{\prime \prime}$ & & - & + \\
$\tilde{A}<A<S$ & $\tilde{A}^{\prime \prime}<A<S^{\prime \prime}$ & & $+/-/ 0$ & $+/-/ 0$ \\
\hline
\end{tabular}

Notes:,,+- 0 denote positive change, negative change, and no effect, respectively.

(5.4) Attorney with high-damage client of type $A \in\left[S^{\prime \prime}, \bar{A}\right]$ :

$$
\gamma\left(A-f_{M}-C_{P}\right)-C_{P}^{2}-\left(C_{P}+f_{M}-x\right) r
$$

\subsubsection{EFFECTS OF A COST-SHIFTING POLICY ON PLAINTIFF'S AND AT- TORNEY'S PAYOFFS}

This section outlines the effects of a cost-shifting policy on the payoffs for the plaintiff and his attorney for Case 1.

Table B1 summarizes the effects of a cost-shifting policy on the payoffs for the plaintiff and his attorney by plaintiff's type position (before and after the policy). Unsurprisingly, most plaintiff's types are worse off. This effect might be explained by the lower equilibrium offer and the high costs for the plaintiff (he now needs to pay a part of the filing and litigation costs). However, for two plaintiff's types, the effect of a cost-shifting policy is ambiguous. In the first case $\tilde{A}^{\prime \prime} \leq A<\tilde{A}$, plaintiff's type $A$ was unable to go to trial before the cost-shift policy was implemented. His expected payoff was $\frac{f_{M}(1-\gamma)}{\gamma}$. After the shift, this type of cases can proceed to trial. The plaintiff's expected payoff is now

$$
\frac{f_{M}}{\gamma S^{\prime \prime}+(1-\gamma) f_{M}}(1-\gamma)\left(S^{\prime \prime}-f_{M}\right)+\left[1-\frac{f_{M}}{\gamma S^{\prime \prime}+(1-\gamma) f_{M}}\right](1-\gamma)\left(A-C_{P}^{1}-f_{M}\right) .
$$

The first term comes from the positive offer made by the defendant, which is smaller than 
$\frac{f_{M}(1-\gamma)}{\gamma}$, the portion of the plaintiff's expected payoff associated with the positive offer before the shift. However, the plaintiff's expected payoff under a cost-shift policy includes another positive term (as the plaintiff's attorney can now proceed to trial). As a result, the overall comparison reveals ambiguity. In the second case, $\tilde{A}^{\prime \prime}<\tilde{A}<A<S^{\prime \prime}<S$, ambiguity is caused by the possibility of lower probability of a zero offer under the cost-shift policy.

The impact of the cost-shifting on the payoff of the attorney is positive for most cases: The attorney shifts some of the cost to his client, which makes him better off. However, when $\tilde{A}^{\prime \prime}<\tilde{A}<A<S^{\prime \prime}<S$, the effect is ambiguous. Although the attorney successfully shifts some of the costs to the plaintiffs, the positive offer to settle is smaller and the probability of the zero offer might be higher under a cost-shifting policy. These last two factors negatively affect the attorney's expected payoff and might offset the positive effect of a cost-shifting policy. 